THE SULPHIDES AND POLYSULPHIDES OF AMMONIUM. 277

\title{
XXXV.—The Sulphides and Polysulphides of
} Ammonium. By W. P. Bloxay, B.Sc. (Lond.), Royal Naval College, Greenwich.

I. Oxidation Changes of Ammonium Hydrosulphide.

Ir is a matter of common experience that the laboratory reagent known as ammonium hydrosulphide or ammonium sulphide is subject to change on contact with air. The solution prepared by saturating aqueous solution of ammonia with hydrogen sulphide is colourless at first, but, on exposure to air, it soon acquires a yellow colour, due to polysulphides; on adding an acid, this solution is decolorised, bydrogen sulphide being evolved, and sulphur deposited. On prolonged exposure to air, the yellow solution loses its colour and deposits sulphur. 
My attention was first directed to the oxidation changes of ammonium hydrosulphide by the failure of a yellow solution to precipitate manganese sulphide on adding it to an aqueous solution of manganous sulphate; the solution was reserved for examination, but, on the following day, it was found to be colourless.

Two distinctly different views have been held as to what takes place during the oxidation. According to the one view, part of the ammonium hydrosulphide is decomposed by oxidation, yielding ammonia, water, and sulphur; of the latter, one portion acts on the remaining ammonium hydrosulphide to form ammonium bisulphide; another portion is oxidised, forming a thiosulphate, whilst the remainder is deposited. The other view assumes that ammonium hydrosulphide is directly oxidised with formation of ammonium bisulphide and thiosulphate in molecular proportion, sulphite and sulphate being formed when the solution becomes colourless.

The first point was to determine what aummonium compounds, other than sulphide and polysulphide, were present, and this involved the removal of sulphide and polysulphide, and the recognition in the filtrate of sulphite, thiosulphate, and sulphate. A scheme for separation is given by Fresenius ("Chemical Analysis-Qualitative, translated by C. E. Groves from the 15th German Edition," p. 194), but it was found to require modification before successful results could be obtained, owing to the difficulty of removing the last traces of bydrogen sulphide. An account of the modified method of analysis will appear in another journal. The experiments made showed that during the oxidation of ammonium hydrosulphide solutions traces of ammonium sulphite are always present, but that sulphate is not formed, ammonium thiosulphate being the end product.

These changes may be explained as follows:-In the first stage, polysulphide alone is formed, for after removal of sulphide and polysulphide by means of cadmium carbonate, the filtrate is free from oxidised sulphur compounds.

At the surface of the liquid some of the aqueous solution of ammonium hydrosulphide is resolved into ammonia, water, and hydrogen sulphide, the latter undergoing oxidation and yielding water and sulphur. This sulphur then acts on ammonium hydrosulphide, forming polysulphide and liberating hydrogen sulphide, the action continuing until the highest polysulphide mixture possible for the concentration is formed. This constitutes the first stage of the action, the maximum colour being developed, and the solution being free from oxidised sulphur. It is not possible to state with certainty whether one polysulphide or a mixture is obtained, but the results of experiments, to be described later, prove that, even when dilute solutions of ammonium hydrosulphide are acted on by sulphur, high 
polysulphides are formed from the first. There is not the slightest ground for supposing ammonium bisulphide to be formed.

In the second stage, the polysulphides are acted on by oxygen, sulphur being liberated.

$$
\left(\mathrm{NH}_{4}\right)_{2} \mathrm{~S}, \mathrm{~S}_{x}+\mathrm{O}=2 \mathrm{NH}_{3}+\mathrm{H}_{2} \mathrm{O}+\mathrm{S}, \mathrm{S}_{x} .
$$

In the third stage, the sulphur acts on ammonia as follows :-

$$
4 \mathrm{NH}_{3}+4 \mathrm{H}_{2} \mathrm{O}+\mathrm{S}_{3}=\left(\mathrm{NH}_{4}\right)_{2} \mathrm{SO}_{3}+2 \mathrm{NH}_{4} \cdot \mathrm{HS}+\mathrm{H}_{2} \mathrm{O},
$$

resulting in the production of ammonium sulphite and hydrosulphide.

In the fourth stage, it will be observed that there are now two modes in which the sulphur may combine, namely, by union with ammonium sulphite, thereby transforming it into thiosulphate, or by acting or the ammonium hydrosulphide whereby more polysulphide is formed.

The absence of ammonium sulphate as an oxidation product is the more remarkable when the great affinity exhibited by ammonium sulphite for oxygen is considered. Experiments with the salt,* $2\left(\mathrm{NH}_{4}\right)_{2} \mathrm{SO}_{3}+3 \mathrm{H}_{2} \mathrm{O}$, show that when moist it is rapidly transformed into sulphate in contact with air, much heat being evolved. On the other hand, the affinity of ammonium sulphite for sulphur is great, a solution of the salt dissolving sulphur with great rapidity, whilst, if crystals of the sulphite be added to a polysulphide solution, the latter is decolorised, the sulphite becoming thiosulphate at the expense of the polysulphide. Seeing that ammonic sulphite exhibits great affinity for both oxygen and sulphur, whilst as an experimental fact no sulphate is formed, it may be possible that the sulphite acquires the sulphur necessary to transform it into thiosulphate from polysulphides present in solution.

With a view to test the above explanation, experiments were made on the action of sulphur on ammonia solution. It was found that in an open vessel strong ammonia solution is not acted on by finely powdered sulphur, even if the solution be boiled. But if ammonia solution be heated with sulphur in a sealed tube in the water bath, action takes place; a solution of polysulphide, of colour intensity increasing with the strength of the ammonia, is obtained, and the solution contains ammonium thiosulphate, but no sulphate, and only traces of sulphite.

Analyses of the products of oxidation of solutions of ammoniam bydrosulphide served to substantiate in general outline the theory of change put forward. At the same time, no means were to hand for

* Being unable to obtain by purchase ammonium sulphite or ammonium thiosulphate in a state of purity, Mr. W. B. Giles kindiy undertook their preparation. and was eminently successful. An account of the preparation and properties of these salts will appear in another journal. 
determining the values of certain necessary factors, namely, the relative proportions of ammonia existing in the free state and as ammonium hydrosulphide, together with the exact nature of the polysulphide present. All that could be done was to determine the relations between total ammonia, sulphur present as sulphide and polysulphide, and the oxidised sulphur.

It is to be noted that in previous accounts of changes occurring no share has been allotted to carbon dioxide in effecting the decomposition of ammonium hydrosulphide and polysulphide solutions. It is found that if pure washed carbon dioxide be passed into solutions of ammonium hydrosulphide, a steady evolution of hydrogen sulphide takes place, and crystals of ammonium hydrogen carbonate are deposited, but no polysulphide is formed. Polysulphides of ammonium are also readily decomposed on passing carbon dioxide through their solutions, hydrogen sulphide being evolved and sulphur deposited.

The paper published by Divers and Shimidzu (Trans., 1884, 45, 270), “On Calcium Hydrosulphides," and by Divers (ibid., 696), "The Origin of Calcium Thinsulphate: an Emendatory Note to a Paper on the Calcium Hydrosulphides," have proved of great assistance in the study of these oxidation changes of ammonium hydrosulphide. The author is in entire agreenent with Divers' remarks on the origin of calcium thiosulphate, as contained in the emendatory note, these being in accord with the present experience.

At this stage it was evident that in order to follow out quantitatively the oxidation changes of solutions of ammonium sulphide, a special study of the various components was necessary.

This entailed the preparation of the hydrosulphides, sulphides, polysulphides, sulphite and thiosulphate of ammonium in a state of purity. The difficulties of analysis and procedure, and the poisonous nature of the gases evolved, probably account for the fact that no work on these compounds has been published since the appearance of the papers by Fritzsche (J. pr. Chem., 1841, 24, 460; ibid., 1844, 32, 313).

It is claimed by the author that, with the exception of ammonium pentasulphide obtained by Fritzsche, none of the ammonium sulphides or polysulphides have previously been prepared in the pure state, or the experimental conditions for their production been investigated.

It should be noted that great care must be taken to avoid inhalation of the vapours of ammonium sulphur compounds, as marked physiological effects are produced, even when small quantities are present in the air respired. Vapours of the ammonium sulphides produce much more serions effects than hydrogen sulphide, the toxic effect being greater in proportion to the volatility of the sulphide; the most. 


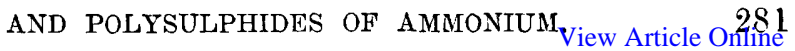

dangerous compound is the volatile oily liquid of the composition, $\left(\mathrm{NH}_{4}\right)_{2} \mathrm{~S}, 2 \mathrm{NH}_{3}$.

\section{Analytical Methods employed.}

Fxperiment soon showed that no pure preparation of any of the ammonium sulphur compounds was available as a control, so that it became necessary to make a series of analyses of solutions to determine whether concordant results could be obtained. The rapidity with which these compounds undergo change on exposure to air renders it necessary to pay close attention to experimental detail, in order to obtain accurate analytical results. This is especially noticeable in the case of polysulphide solutions.

Determination of Total Sulphur.-It is well known that barium sulphate exhibits a great tendency to carry down with it other salts, and in consequence, to obtain accurate results, it was found necessary to exclude, from the solutions, substances, either known to exercise a solvent action on bariam sulphate or liable to be carried down with it during precipitation; care also had to be taken in adjusting the quantities of the reagents employed.

Among oxidising agents, an ammoniacal solution of hydrogen peroxide is greatly to be preferred, but unfortunately commercial samples of hydrogen peroxide contain impurities, such as sulphuric acid, phosphoric acid, nitrite, phosphate, alumina, \&c., which might interfere with the results. Oxidation was consequently effected by means of acid or alkaline solutions of bromine, preferably a solution of sodic hypobromite, the process being conducted as follows.

Fifty c.c. of a solution of sodic hydroxide (100 grams $\mathrm{NaHO}$ dissolved in 1000 grams $\mathrm{H}_{2} \mathrm{O}$ ) are placed in a tolerably capacious beaker, and pure bromine added in slight excess. The sulphide or polysulphide solution, or crystals (containing about 0.6 gram of sulphur) are rapidly weighed in a small stoppered weighing tube, then quickly transferred to the beaker, and the tube rinsed repeatedly with water. In cases where contact with water decomposes the polysulphides, the film of sulphur deposited in the weighing tube is dissolved by bromine water, and washed into the beaker. The whole is weil agitated in the cold until the finely divided sulphur first precipitated is dissolved, and the solution is then gently warmed for some hours on a sand bath. Great care must be taken to prevent precipitation of sulphur, which, assuming the globular form, is only very slowly acted on by the bromine. When complete solution is effected, sufficient hydrochloric acid is added to decompose the excess of hypobromite, and the bromine is expelled by heat.

In the meantime the determination of ammoniam is made, using standard sulphuric acid, and from this the approximate quantity of 
barium chlnride required to effect precipitation could be calculated. The required quantity of hot barium chloride solution (containing 10 per cent. $\mathrm{BaCl}_{2}, 2 \mathrm{H}_{2} \mathrm{O}$ ) is then run in, and the beaker and contents allowed to stand over-night. The precipitate and filter paper must be ignited separately, and the ash treated with a few drops of bromine water, and again ignited before adding it to the main portion. With these precautions, the barium sulphate is always pure, and the results are entirely satisfactory. Where bromine in acid solution is used as the oxidising agent, the same routine is followed, with one exception; before adding barium chloride, the solution is neutralised with ammonia, and then rendered slightly acid with hydrochloric acid.

It is unnecessary to expel all the bromine by evaporating the solution nearly to dryness before adding the barium chloride (see Lucion, Chem. Zeit., 1888, 12,427, and G. Tauber, ibid., 477 ; I can confirm their results).

Determination of Polysulphide Sulphur.-The solution or the erystals are rapidly transferred to a small stoppered weighing tube and the weight determined; the solution is then washed into a beaker containing a slight excess of dilute hydrochloric acid containing no free chlorine. The beaker, loosely covered, is then gradually heated upon a sand bath until no more hydrogen sulphide is evolved. The liquid is allowed to cool, and oxidation of the sulphur is effected by bromine, in the manner previously described.

As already noticed, solutions containing tetrasulphide or higher sulphides always deposit sulphur in the weighing tube during the process of dilution and transference to the beaker; this is dissolved in bromine water and added to the oxidising mixture in the beaker. The determinations of polysulphide sulphur made in this manner are accurate. According to the older methods, the sulphur, present as sulphide and polysulphide, is precipitated by a zinc salt; the precipitate is boiled with acid, and the residue of sulphur is oxidised and determined as barium sulphate. Amongst other disadvantages, the results were invariably high, owing to the precipitated barium sulphate retaining zinc salt.

Determination of Ammonium.- Since the determination of the anmonium as a platinochloride involved the sacrifice of much time, the following method was adopted, giving the ammonium value rapidly.

Standard solutions of normal and N/10 sulphuric acid were prepared, and also a $N / 10$ solution of potassium hydroxide. The solution to be analysed was rapidly weighed, washed into a flask containing excess of the standard acid, and then heated and maintained at the boiling point until bydrogen sulphide ceased to be evolved, the excess 
of acid in the hot solution being determined by the standard alkali, using litmus as indicator. This method gives very accurate results, and a complete determination can be effected in less than half an hour. When a polysulphide is treated in the manner described, the sulphur which is deposited coagulates when the acid solution is boiled, and settles to the bottom of the flask; its presence does not, however, in any way interfere with the determination of the point of neutrality.

Time is saved if methyl-orange be employed as indicator, it being unnecessary to expel the hydrogen sulphide by boiling, but the results are not quite so accurate; using this method, the weighed sulphide solution is washed into a flask containing cold water, methyl-orange is added, and standard acid run in until the characteristic colour change is observed. As, however, the evolution of hydrogen snlphide during the titration is objectionable, it is better to employ the process first mentioned.

\section{Preparation of Solution of Ammonium Hydrosulphide.}

Compounds formed on passing Hydrogen Sulphide through a concentrated solution of Ammonia (sp. gr. 0.880).-A strong solution of am. monium hydrosulphide being required for the preparation of the ammonium polysulphides as decribed by Fritzsche (J.pr. Chem., 1841, $24,460 ; 1844,32,313)$, the method generally recommended was employed.

A current of washed hydrogen sulphide was passed through 300 c.c.

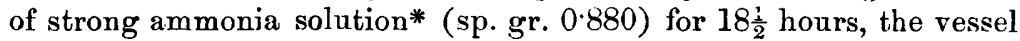
containing the liquid being surrounded by cold water. When hydrogen sulphide escaped freely from the outlet tube, a portion of the solution was analysed. It was found to contain $\mathrm{S}=27 \cdot 75$ and $27 \cdot 66$ per cent., $\mathrm{NH}_{4}=20.33$ and $20 \cdot 30$ per cent.

A solution of ammonium hydrosulphide would require 36.11 per cent. sulphur to 20.3 of ammoniam. The solution obtained being deficient in sulphur to the extent of 8.4 per cent., it was inferred that saturation was not complete.

A second similar experiment was made, but the stream of gas was maintained for 24 hours after the gas ceased to be absorbed. Analysis gave $\mathrm{S}=28 \cdot 11$ and 28.20 per cent. $\mathrm{NH}_{4}=22.47$ and 22.40 per cent. A solntion of ammonium hydrosulphide of this strength requires 39.91 per cent. of sulphur.

These experiments prove:-

(a.) That strong ammonia solutions do not absorb the amount of

* Throughout this paper the expression "strong ammonia solution" refers to "Liq. Ammon. Fortiss., sp. gr. 0*880." 
hydrogen sulphide necessary for the complete conversion of the ammonia into ammonium hydrosulphide.

(b.) That the stronger the solntion of ammonia the less sulphur relatively is taken up.

In the first experiment, the end product contains 20.3 per cent. ammonium and 76.7 per cent. of the sulphur required to form $\mathrm{NH}_{4} \cdot \mathrm{HS}$. In the second experiment, the end product contains $22 \cdot 47$ per cent. ammonium and only 71.2 per cent. of the sulphur required to form $\mathrm{NH}_{4} \cdot \mathrm{HS}$.

In order to determine the nature of the product obtained on saturating a solution of ammonia (sp.gr. 0.880 ) with hydrogen sulphide, a portion of the solution was cooled by a freezing mixture of ice and salt. Leaf-like crystals were deposited which, after being drained as completely as possible from the mother liquor, were allowed to dissolve in their water of hydration, dissolution being aided by placing the bottle in slightly warm water. On standing, this clear solution deposited crystals; these on analysis gave $\mathrm{S}=30.08$ per cent.; $\mathrm{NH}_{4}=22.62$ per cent.

For $\mathrm{NH}_{4} \cdot \mathrm{HS}, 40 \cdot 21$ per cent. of sulphur would be required; the crystals, therefore, contain only three-quarters the amount of sulphur required by the formula $\mathrm{NH}_{4} \cdot \mathrm{HS}$, and their composition may be represented as $\left(\mathrm{NH}_{4}\right)_{2} \mathrm{~S}, 2 \mathrm{NH}_{4} \cdot \mathrm{HS}$. A saturated aqueous solution of this substance contains $52 \cdot 7$ per cent. of the compound.

From this it is seen that the product obtained on saturating solution of ammonia (sp. gr. 0.880) with hydrogen sulphide at the ordinary temperature is not $\mathrm{NH}_{4} \cdot \mathrm{HS}$ but $\left(\mathrm{NH}_{4}\right)_{2} \mathrm{~S}, 2 \mathrm{NH}_{4} \cdot \mathrm{HS}$.

A solution of $\left(\mathrm{NH}_{4}\right)_{2} \mathrm{~S}, 2 \mathrm{NH}_{4} \cdot \mathrm{HS}$ cooled to $0^{\circ}$ absorbs hydrogen sulphide, and fern-like crystals are deposited. After complete saturation at $0^{\circ}$, analyses were made of the crystals and of the mother liquor.

The mother liquor gave $\mathrm{S}=27.01$ and 27.53 per cent.; $\mathrm{NH}_{4}=$ 17.7:3 per cent. and 17.75 per cent., corresponding to the formula $\left(\mathrm{NH}_{4}\right)_{2} \mathrm{~S}, 6 \mathrm{NH}_{4} \cdot \mathrm{HS}$, for which $17 \cdot 74$ per cent. $\mathrm{NH}_{4}$ requires $27 \cdot 60$ per cent. S.

A solution of the crystals gave $\mathrm{S}=23 \cdot 11$ and $23 \cdot 16$ per cent.; $\mathrm{NH}_{4}=14.03$ and 14.00 per cent., corresponding to the formula $\left(\mathrm{NH}_{4}\right)_{2} \mathrm{~S}, 12 \mathrm{NH}_{4} \cdot \mathrm{HS}$, for which $14 \cdot 0$ per cent. $\mathrm{NH}_{4}$ requires $23 \cdot 12$ per cent. S.

When washed hydrogen sulphide was passed into ammonia solution of sp. gr. $0.880 \mathrm{kept}$ at $0^{\circ}$, white crystalline scales began to form on the surface cf the liquid after the lapse of a considerable time; the current of gas was maintained until no further formation of crystals was observed, the flask being now half full of white crystalline plates resembling potassic chlorate in appearance. Analyses were then made of the mother liquor and of the crystals. 


\section{AND POLYSULPHIDES OF AMMONIUM ${ }_{\text {View Article Online }}$}

The mother liquor, which effervesced freely, was found to contain $\left(\mathrm{NH}_{4}\right)_{2} \mathrm{~S}, 6 \mathrm{NH}_{4} \cdot \mathrm{HS}$.

The crystals bore pressure between filter paper, being hard and crisp to the touch, a marked contrast to the behaviour of the com. pound $\left(\mathrm{NH}_{4}\right)_{2} \mathrm{~S}, 12 \mathrm{NH}_{4} \cdot \mathrm{HS}$ under similar circumstances. The values obtained were $\mathrm{S}=57.47$ per cent. $\mathrm{NH}_{4}=34 \cdot 13$ and 34.05 per cent., corresponding to the formula $\left(\mathrm{NH}_{4}\right)_{2} \mathrm{~S}, 18 \mathrm{NH}_{4} \cdot \mathrm{HS}+4 \mathrm{H}_{2} \mathrm{O}$, which requires $\mathrm{S}=57.47 ; \mathrm{NH}_{4}=34.02$ per cent.

From these experiments, it is seen that the current statement that an aqueous solution of $\mathrm{NH}_{4} \cdot \mathrm{HS}$ is obtained by saturating $\mathrm{NH}_{3}+\mathrm{Aq}$ with hydrogen sulphide in absence of air, is only true when the value of $\mathrm{Aq}$ is defined. If $\mathrm{NH}_{3}+\mathrm{Aq}$ be interpreted as solution of ammonia of sp. gr. 0.880 , then in no case can a solution of $\mathrm{NH}_{4} \cdot \mathrm{HS}$ be obtained on passage of $\mathrm{H}_{2} \mathrm{~S}$. In its place a number of compounds are obtained to which the general form $\left(\mathrm{NH}_{4}\right)_{2} \mathrm{~S}, x \mathrm{NH}_{4} \cdot \mathrm{HS}$ may be given.

Experiments made to determine at what degree of Dilution, if any, $\mathrm{NH}_{4} \cdot \mathrm{HS}$ is formed on saturating Solution of Ammonia with Hydrogen Sulphide.

The foregoing experiments indicated the probability that in dilute solutions of ammonia the amount of hydrogen sulphide requisite for the formation of ammonium hydrosulphide might be absorbed. This was proved to be the case, for on making a dilute solution in ice-cold water of the crystals $\left(\mathrm{NH}_{4}\right)_{2} \mathrm{~S}, 12 \mathrm{NH}_{4} \cdot \mathrm{HS}$, and passing a current of hydrogen sulphide for 24 hours through the solution cooled at $0^{\circ}$, analysis showed that the ammonium and sulphur in the solution were in the proportion required by the formula $\mathrm{NH}_{4} \cdot \mathrm{HS}$.

Experiments were now made to determine at what degree of dilution $\mathrm{NH}_{4} \cdot \mathrm{HS}$ is formed on saturating ammonia solution with

Solutions Cooled to $0^{\circ}$ and Saturated with Hydrogen Sulphide.

\begin{tabular}{|c|c|c|c|c|c|}
\hline \multicolumn{2}{|c|}{$\begin{array}{l}\text { Degree } \\
\text { of dilution. }\end{array}$} & \multicolumn{2}{|c|}{$\begin{array}{l}\text { Results of analysis of } \\
\text { saturation product. }\end{array}$} & \multirow{2}{*}{$\begin{array}{l}\text { Percentage of } \\
\mathrm{S} \text { in satu- } \\
\text { ration product. } \\
\mathrm{S} \text { in } \mathrm{NH}_{4} \cdot \mathrm{HS} \\
=100 .\end{array}$} & \multirow{2}{*}{$\begin{array}{l}\text { Composition of } \\
\text { saturation product. }\end{array}$} \\
\hline $\begin{array}{c}\text { Vols, : } 0.88 \\
\text { ammonia } \\
\text { solution. }\end{array}$ & $\begin{array}{l}\text { Vols. : } \\
\text { Water. }\end{array}$ & $\begin{array}{c}\mathrm{NH}_{4} \\
\text { per cent. }\end{array}$ & $\mathbf{S}$ per cent. & & \\
\hline $\begin{array}{crr}\text { No. } & \text { I } & 3 \\
, & \text { II } & 2 \\
, & \text { III } & 1 \\
, & \text { IV } & 1 \\
, & \text { V } & 1 \\
, & \text { VI } & 1 \\
, & \text { VII } & 1\end{array}$ & $\begin{array}{l}1 \\
1 \\
1 \\
2 \\
3 \\
4 \\
5\end{array}$ & 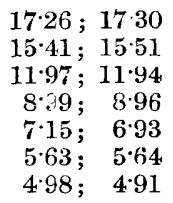 & $\begin{array}{c}25 \cdot 11 ; 25 \cdot 06 \\
24 \cdot 75 ; 25 \cdot 01 \\
19 \cdot 16 ; 19.08 \\
15 \cdot 18 ; 15 \cdot 20 \\
11.89 ; 11 \cdot 80 \\
9 \cdot 93 \\
8.67 ; 8.66\end{array}$ & $\begin{array}{r}81 \cdot 6 \\
90 \cdot 1 \\
90 \cdot 0 \\
95 \cdot 0 \\
95 \cdot 2 \\
100 \cdot 0 \\
100 \cdot 0\end{array}$ & $\begin{array}{c}\left(\mathrm{NH}_{4}\right)_{2} \mathrm{~S}, 4 \mathrm{NH}_{4} \cdot \mathrm{HS} \\
\left(\mathrm{NH}_{4}\right)_{2} \mathrm{~S}, 8 \mathrm{NH}_{4} \cdot \mathrm{HS} \\
\left(\mathrm{NH}_{4}\right)_{2} \mathrm{~S}, 8 \mathrm{NH}_{4} \cdot \mathrm{HS} \\
\left(\mathrm{NH}_{4}\right)_{2} \mathrm{~S}, 18 \mathrm{NH}_{4} \cdot \mathrm{HS} \\
\left(\mathrm{NH}_{4}\right)_{2} \mathrm{~S}, 18 \mathrm{NH}_{4} \cdot \mathrm{HS} \\
\mathrm{NH}_{4} \cdot \mathrm{HS} \\
\mathrm{NH}_{4} \cdot \mathrm{HS}\end{array}$ \\
\hline
\end{tabular}


hydrogen sulphide. The results are, for convenience, appended in the tabular form.

It appears from these experiments that ordinary strong solution of ammonia must be diluted with about four times its volume of water before the full amount of hydrogen sulphide required to form ammonium hydrosulphide is absorbed. The strongest solution of ammonium hydrosulphide contains less than 19 per cent. $\mathrm{NH}_{4} \cdot \mathrm{HS}$ (see Experiment V). The solution obtained when the dilution was $1: 4$ (see Experiment VI) contained 16 per cent. $\mathrm{NH}_{4} \cdot \mathrm{HS}$. The strongest solution of ammonium hydrosulphide obtainable contains, therefore, between 16 and 19 per cent. of $\mathrm{NH}_{4} \cdot \mathrm{HS}$.

\section{Attempts to prepare Ammonium Hydrosulphide in the Solid State.}

It is stated on the authority of Bineau (Ann. Chim. Phys., $1838,67,230 ; 1838,68,435)$ that, at ordinary temperatures, hydrogen sulphide and gaseous ammonia combine in equal volumes in whatever proportions they may be mixed. The compound crystallises in colourless needles and scales, and volatilises and sublimes, even at ordinary temperatures; it has a penetrating odour of ammonia and of hydrogen sulphide, and an alkaline action; rapidly turns yellow on exposure to the air, from formation of pentasulphide of ammonium (Thénard); it yields a colourless solution with water. As no analyses of this compound are given, it was determined to repeat the experiment. A wide-mouth bottle was fitted with a cork and two glass tubes to serve as inlets for the hydrogen sulphide and ammonia respectively, whilst a third tube served as an outlet for the escape of gases. On passing the gases, ammonia being in excess, into the bottle cooled with ice, colourless needles and scales were formed; but the greater portion was deposited on the sides of the bottle as a white, porcelain-like mass.

Attention was directed especially to the question, is $\mathrm{NH}_{4} \cdot \mathrm{HS}$ the only product obtained? In order to test this point, ice-cold water was introduced into the bottle containing the white crystalline solid; three solutions were made in rapid succession and numbered I, II, and III, No. I being the weakest, and No. III the strongest.

The crystals being assumed to be $\mathrm{NH}_{4} \cdot \mathrm{HS}$, analysis of the solutions should show either that all three had the same composition as the crystals, that is, $\mathrm{NH}_{4} \cdot \mathrm{HS}$, showing that ammonium hydrogen sulphide when once formed will yield concentrated aqueous solutions without loss of bydrogen sulphide, or that, as previously experienced, the existence of $\mathrm{NH}_{4} \cdot \mathrm{HS}$ as such, in concentrated aqueous solutions, is not possible, hydrogen snlphide being evolved.

The results of the analysis of the three solutions are given below. 


\begin{tabular}{|c|c|c|c|}
\hline & $\begin{array}{l}\mathrm{NH}_{4} \\
\text { per cent. }\end{array}$ & $\mathbf{S}$ per cent. & $\begin{array}{l}\text { Percentage of } \mathrm{S} \text { present. } \\
\mathrm{S} \text { in } \mathrm{NH}_{4} \cdot \mathrm{HS}=100 .\end{array}$ \\
\hline 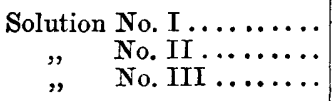 & $\begin{array}{r}3 \cdot 85 \\
8 \cdot 55 \\
16 \cdot 10\end{array}$ & $\begin{array}{c}6 \cdot 0 \\
13 \cdot 48 \\
22 \cdot 87\end{array}$ & $\begin{array}{l}87 \cdot 5 \\
88 \cdot 4 \\
79 \cdot 7\end{array}$ \\
\hline
\end{tabular}

These analyses show that the crystals obtained were not pure $\mathrm{NH}_{4} \cdot \mathrm{HS}$, as the solution No. I, which is within the dilution limit previously determined for $\mathrm{NH}_{4} \cdot \mathrm{HS}$ (see p. 286), had not this composition, but contained only 88 per cent. of the sulphur required for $\mathrm{NH}_{4} \cdot \mathrm{HS}$. From this it is evident that, contrary to Bineau's statement (loc. cit.), it is not a matter of indifference whether the volumes of the gases are adjusted or not.

A second preparation was therefore made, in which the hydrogen sulphide was kept in slight excess, the other details being similar to those of the preceding experiment. The crystals thus formed were not to be distinguished in appearance from those obtained in the previous experiment; on analysis, however, they proved to be $\mathrm{NH}_{4} \cdot \mathrm{HS}$, the analysis of the solution of the crystals giving $\mathrm{NH}_{4}=$ 6.23 per cent., $\mathrm{S}=10.57$ per cent., corresponding to

$$
\left(\mathrm{NH}_{4}\right)_{2} \mathrm{~S}, 18 \mathrm{NH}_{4} \cdot \mathrm{HS} \text {, }
$$

derived from the action of water on $\mathrm{NH}_{4} \cdot \mathrm{HS}$, the solution being too concentrated for the existence in it of $\mathrm{NH}_{4} \cdot \mathrm{HS}$ (see p. 286).

Ammonium hydrosulphide can, therefore, be prepared in a state of purity by this method, if the volumes of the gases are equal, or if the hydrogen sulphide is in slight excess, but not if the ammonia is in excess.

Only one other method is given for the preparation of ammonium hydrosulphide, namely, by passing hydrogen sulphide into an alcoholic solution of ammonia.

To investigate this method, absolute alcohol was saturated with dry ammonia, and washed hydrogen sulphide was passed into the alcoholic solution kept at $0^{\circ}$. The large, white, micaceous plates which formed were separated from the mother liquor, and the crystals dried by pressure between filter-paper. The odour exhaled is almost insupportable.

Analyses were made of the crystals and of their solutions in water. The conclusions arrived at are :-

1. This method does not yield $\mathrm{NH}_{4} \cdot \mathrm{HS}$, but substances containing less sulphur than is required by the formula $\mathrm{NH}_{4} \cdot \mathrm{HS}$.

2. These substances are of the same nature as those obtained on saturating aqueous solutions of ammonia with hydrogen sulphide, voL. LXYII. 
$\left(\mathrm{NH}_{4}\right)_{2} \mathrm{~S}, x \mathrm{NH}_{4} \cdot \mathrm{HS}$. The product obtained from alcoholic solution varies according to the strength of the solution.

3. The crystals obtained contain alcohol.

\section{Ammonium Monosulphide.}

Experiments were now made with the view of ascertaining whether a strong ammonia solution, when supplied with the amount of hydrogen sulphide required to form $\left(\mathrm{NH}_{4}\right)_{2} \mathrm{~S}$, would yield a solution of this substance, or whether the product would behave as a mixture of ammonia and one of the compounds of the type $\left(\mathrm{NH}_{4}\right)_{2} \mathrm{~S}, x \mathrm{NH}_{4} \cdot \mathrm{HS}$ previously described. The usual method for preparing a solution of ammonium monosulphide, namely, to divide a quantity of aqueous ammonia into two equal parts, saturate one with hydrogen sulphide, and then add the otber to it, is useless for making a concentrated solution, as the compound will contain an excess of ammonia. To determine the ammonia and sulphur in the portion saturated, and then to add the required quantity of titrated ammonia solution, is open to the objection that the product obtained on saturation of 0.880 ammonia solution, e.g., $\left(\mathrm{NH}_{4}\right)_{2} \mathrm{~S}, 2 \mathrm{NH}_{4} \cdot \mathrm{HS}$, might not be acted on by the ammonia added, and the two would then exist separately in the solution.

The other method for making the solution, namely, to pass hydrogen salphide in quantity just sufficient to form ammonium monosulphide, entails analysis of the solation at intervals, in order to guard against the introduction of excess of hydrogen sulphide. It is evident that a rapid and accurate method of determining when the monosulphide limit has been reached is required.

Divers and Shimidzu (Trans., 1884, 45, 275) have employed manganous salts for the detection of basylous hydrogen in such cases, the test being based upon the following reactions,

$$
\begin{aligned}
\left(\mathrm{NH}_{4}\right)_{2} \mathrm{~S}+\mathrm{MnSO}_{4} & =\mathrm{MnS}+\left(\mathrm{NH}_{4}\right)_{2} \mathrm{SO}_{4}, \\
2 \mathrm{NH}_{4} \cdot \mathrm{HS}+\mathrm{MnSO}_{4} & =\mathrm{MnS}+\left(\mathrm{NH}_{4}\right)_{2} \mathrm{SO}_{4}+\mathrm{H}_{2} \mathrm{~S},
\end{aligned}
$$

half the sulphur present as hydrosulphide escaping precipitation, and appearing as hydrogen sulphide. This method, however, has not proved satisfactory in the author's hands, owing to the fact that the reaction does not take place sharply. The test is made by adding the solution to be examined to an excess of a solution of a manganous salt, contained in a stoppered glass cylinder, which is then closed and shaken, and, after an interval, a piece of lead paper is introduced into the air in the cylinder. It was found, however, that, even when the ammonia was in excess, some time elapsed before the air was free from hydrogen sulphide, and as the solution approaches the monosulphide imit, it is difficult to determine whether the hydrogen sul- 
phide in the air arises from undecomposed ammonium monosulphide or is due to the presence of hydrosulphide. A magnesium salt is Jecommended for the detection of excess of ammonia, but the reagent proved to be useless, as the presence of ammonium sulphide prevents the precipitation of magnesium hydroxide.

These difficulties have been overcome by employing a solution of cupric sulphate, and it is possible by its use to determine qualitatively or quantitatively any excess, either of ammonia or of hydrogen sulphide, over and above that required to form ammonium monosulphide. The following reactions may occur.

$$
\begin{aligned}
& \text { (a.) } 2 \mathrm{CnSO}_{4}+2 \mathrm{NH}_{4} \cdot \mathrm{HS}=2 \mathrm{CuS}+\left(\mathrm{NH}_{4}\right)_{2} \mathrm{SO}_{4}+\mathrm{H}_{2} \mathrm{SO}_{4} \cdot \\
& \text { (b.) } \mathrm{CuSO}_{4}+\left(\mathrm{NH}_{4}\right)_{2} \mathrm{~S}=\mathrm{CuS}+\left(\mathrm{NH}_{4} \mathrm{SO}_{4} .\right. \\
& \text { (c.) } 2 \mathrm{CuSO}_{4}+\left(\mathrm{NH}_{4}\right)_{2} \mathrm{~S}+2 \mathrm{NH}_{4} \mathrm{HO}=\mathrm{CuS}+ \\
& +\mathrm{Cu}(\mathrm{HO})_{2} \\
& +2\left(\mathrm{NH}_{4}\right)_{2} \mathrm{SO}_{4} \cdot
\end{aligned}
$$

The examination is made as follows. An excess of solution of recrystallised cupric sulphate $\left(1\right.$ c.c. $=$ about $0 \cdot 1$ gram $\mathrm{CuSO}_{4}$ ) is placed in a flask, water is added, and the solution to be examined is run in. The flask is closed by a tightly-fitting cork, and the flask and contents shaken; the reaction is rery sharp, and the air in the flask, after once shaking, is invariably free from hydrogen sulphide. The superuatant liquor is filtered, and the precipitate remaining in the flask is washed with hot water by decantation until free from acidity and copper salt. The filtrate is allowed to cool, and titrated with decinormal solution of potassic hydroxide. If the first drops produce a turbidity, showing that the mixture has not become acid, ammonia solution is added to the precipitate remaining in the flask, which is well shaken. On filtering, a deep blue solution is obtained, showing that an excess of ammonia orer that required to form ammonium monosulphide was present. A solution containing ammonia and hydrogen sulphide in the exact proportions required by ammonium monosulphide develops no acidity, and the precipitate, after treatment with ammonia, does not yield a blue filtrate.

'lo determine any excess of ammonia quantitatively, it is only necessary to add to the cupric sulphate solution in the flask an excess of standard acid, and to proceed as above, the difference between the acid taken and that found by titration corresponding to the excess of ammonia present. The reagent is specially valuable for the examination of polysulphide solutions, and gives accurate results when used quantitatively. The determinations of the sulphur in commercial samples of ammonium hydrosulphide can be rapidly effected by this method.

Being now in a position to determine readily when the amount of 
hydrogen sulphide required to form ammonium monosulphide had been taken up, a solution was made by passing a current of washed. hydrogen sulphide through a strong solution of ammonia, cooled to $0^{\circ}$. Test samples were taken from time to time, and treated with cupric sulphate solution, and when the neutral point was reached the solution was analysed in the usual way, the following values being obtained, $\mathrm{NH}_{4}=25.88$ and 25.95 per cent., $\mathrm{S}=22.91$ and 22.80 per eent. This is in the proportion required by ammonium monosulphide. For $\left(\mathrm{NH}_{4}\right)_{2} \mathrm{~S}$ the ammonium found would require $\mathrm{S}=23.02$ per cent.

An attempt to obtain crystals by cooling the solution even at $-40^{\circ}$ was unsuccessful, but it is worthy of note that in all cases where free ammonia was present it exercised a great solvent power, tending to prevent the deposition of crystals. Is then the solution which gives analytical results pointing to $\left(\mathrm{NH}_{4}\right)_{2} \mathrm{~S}$ a solution of this substance, or is it to be regarded as a mixture of a compound of the type $\left(\mathrm{NH}_{4}\right)_{2} \mathrm{~S}, x \mathrm{NH}_{4} \cdot \mathrm{HS}$ with $x \mathrm{NH}_{4} \cdot \mathrm{HO}$ ? If the solution be saturated with hydrogen sulphide, the compound formed has the composition $\left(\mathrm{NH}_{4}\right)_{2} \mathrm{~S}, 2 \mathrm{NH}_{4} \cdot \mathrm{HS}$, and crystals of this substance can be obtained from it; that is to say, the supposed solution of $\left(\mathrm{NH}_{4}\right)_{2} \mathrm{~S}$ only takes up half the amount of hydrogen sulphide required to form $\mathrm{NH}_{4} \cdot \mathrm{HS}$.

On diluting the original solution with varying quantities of water, and then passing hydrogen sulphide to saturation, the amount of the gas absorbed does not progressively increase with the dilution, but solutions of the composition $\left(\mathrm{NH}_{4}\right)_{2} \mathrm{~S}, 4 \mathrm{NH}_{4} \cdot \mathrm{HS},\left(\mathrm{NH}_{4}\right)_{2} \mathrm{~S}, 8 \mathrm{NH}_{4} \cdot \mathrm{HS}$, $\left(\mathrm{NH}_{4}\right)_{2} \mathrm{~S}, 18 \mathrm{NH}_{4} \cdot \mathrm{HS}$, and, finally, $\mathrm{NH}_{4} \cdot \mathrm{HS}$ ure obtained.

The amount of hydrogen sulphide absorbed always corresponds with one of these compounds, and no intermediate ratios are obtained. For example, the solution $\left(\mathrm{NH}_{4}\right)_{2} \mathrm{~S}, 8 \mathrm{NH}_{4} \cdot \mathrm{HS}$ will not absorb more hydrogen sulphide on progressive dilution; when, however, a certain stage of dilution is reached absorption once more takes place, and a solution of the compound $\left(\mathrm{NH}_{4}\right)_{2} \mathrm{~S}, 18 \mathrm{NH}_{4} \cdot \mathrm{HS}$ can be obtained.

On the assumption that only the compounds $\left(\mathrm{NH}_{4}\right)_{2} \mathrm{~S}$ and $\mathrm{NH}_{4} \cdot \mathrm{HS}$ exist, and that the amount of hydrogen sulphide absorbed depends on the amount of the $\left(\mathrm{NH}_{4}\right)_{2} \mathrm{~S}$, which is dissociated, it seems impossible to explain why only solutions corresponding with the compounds above mentioned can be obtained.

On the other hand, it is easy to understand the process of absorption of hydrogen sulphide, if the existence of definite compounds of the type $\left(\mathrm{NH}_{4}\right)_{2} \mathrm{~S}, x \mathrm{NH}_{4} \cdot \mathrm{HS}$ be admitted. Crystals of the composition $\left(\mathrm{NH}_{4}\right)_{2} \mathrm{~S}, 2 \mathrm{NH}_{4} \cdot \mathrm{HS}, \quad\left(\mathrm{NH}_{4}\right)_{2} \mathrm{~S}, 12 \mathrm{NH}_{4} \cdot \mathrm{HS}, \quad\left(\mathrm{NH}_{4}\right)_{2} \mathrm{~S}, 18 \mathrm{NH}_{4} \cdot \mathrm{HS}$ have actually been obtained.

Moreover, if crystals of $\mathrm{NH}_{4} \cdot \mathrm{HS}$ be treated, in a stoppered bottle, with water, then-if the quantity of water be less than is required for 
a solution of $\mathrm{NH}_{4} \cdot \mathrm{HS}$, as found by direct saturation (see table, p. 285) -au evolution of hydrogen sulphide is observed : a point of stability being reached when the solution corresponds with the compound of the type $\left(\mathrm{NH}_{4}\right)_{2} \mathrm{~S}, x \mathrm{NH}_{4} \cdot \mathrm{HS}$ possible at the degree of dilution.

The explanation of the observed facts offered by the author is as follows. When hydrogen suiphide is passed into ammonia solution $\left(\mathrm{NH}_{4}\right)_{2} \mathrm{~S}$ is first formed, and this breaks down giving $\mathrm{NH}_{4} \cdot \mathrm{HS}$ and $\mathrm{NH}_{4} \cdot \mathrm{HO}$. The $\mathrm{NH}_{4} \cdot \mathrm{HS}$ thus produced unites with more $\left(\mathrm{NH}_{4}\right)_{2} \mathrm{~S}$ to form compounds of the general formula $\left(\mathrm{NH}_{4}\right)_{2} \mathrm{~S}, x \mathrm{NH}_{4} \cdot \mathrm{HS}$, the value of $e$ increasing with the dilution of the solution. With the strongest ammonia solution, the saturated product has the composition $\left(\mathrm{NH}_{4}\right)_{2} \mathrm{~S}, 2 \mathrm{NH}_{4} \cdot \mathrm{HS}$, and when the saturated solution contains only about 6 per cent. of ammonium, the full amount of hydrogen sulphide required to form $\mathrm{NH}_{4} \cdot \mathrm{HS}$ is absorbed. Within certain tolerably wide limits of dilution, the value of $x$ remains constant, and the solutions do not progressively take up more hydrogen sulphide (see table, p. 285).

Even if the current of hydrogen salphide be not continued to complete saturation of the solution, the product corresponding to the dilution alone will be formed, the excess of ammonia remaining free; thus (vide $\dot{\mathrm{p}}$. 296) the solution yielding analytical figures for $\left(\mathrm{NH}_{4}\right)_{2} \mathrm{~S}$ is to be regarded as one of $\left(\mathrm{NH}_{4}\right)_{2} \mathrm{~S}, 2 \mathrm{NH}_{4} \cdot \mathrm{HS}+2 \mathrm{NH}_{4} \cdot \mathrm{HO}$ Thus, although neither $\mathrm{NH}_{4} \cdot \mathrm{HS}$ nor $\left(\mathrm{NH}_{4}\right)_{2} \mathrm{~S}$ exist as such in concentrated solutions, the two combine together, forming compounds of considerable stability, their solutions being incapable of taking up more hydrogen sulphide until they are furthur diluted. The crystals of $\left(\mathrm{NH}_{4}\right)_{2} \mathrm{~S}, 18 \mathrm{NH}_{4} \cdot \mathrm{HS}$ which have been obtained are well defined and are fairly stable. This view of the constitution of the supposed solution of ammonium monosulphide-namely, that it is a mixture of $\left(\mathrm{NH}_{4}\right)_{2} \mathrm{~S}, 2 \mathrm{NH}_{4} \cdot \mathrm{HS}+2 \mathrm{NH}_{4} \cdot \mathrm{HO}$-receives ample experimental confirmation. In the first place, its behaviour with solution of cupric sulphate is intelligible. Secondly, the failure of the solution to yield crystals by cooling can be attributed to the known solvent action exercised by free ammonia. In the third place, the solution exhibits no tendency to dissolve sulphur in the simple fashion attribated to the monosulphide, thus-

$$
\left(\mathrm{NH}_{4}\right)_{2} \mathrm{~S}+\mathrm{S}_{1} \ldots \mathrm{S}_{2}, \& \mathrm{c} .,=\left(\mathrm{NH}_{4}\right)_{2} \mathrm{~S}_{2} \ldots \mathrm{S}_{3} \text {, \&c. }
$$

On the contrary, as is described later, the solution, when treated in the cold with finely-divided sulphur, evolves hydrogen sulphide, and when rather more sulphur has gone into solution than is required to form $\left(\mathrm{NH}_{4}\right)_{2} \mathrm{~S}_{2}$, a crystalline compound is obtained which has invariably the composition of tetrammonium heptasulphide, $\left(\mathrm{NH}_{4}\right)_{4} \mathrm{~S}_{7}$, in which five of the sulphur atoms are not in direct union with ammonium. 
The formation of this compound is intelligible, if the composition of the supposed ammonium monosulphide solution be

$$
\left(\mathrm{NH}_{4}\right)_{2} \mathrm{~S}, 2 \mathrm{NH}_{4} \cdot \mathrm{HS}+2 \mathrm{NH}_{4} \cdot \mathrm{HO} \text {. }
$$

On treating the compound $\mathrm{NH}_{\mathrm{NH}_{4}}^{\mathrm{NH}_{4}}>\mathrm{S} \ll_{\mathrm{SH} \cdot \mathrm{NH}_{4}}^{\mathrm{SH} \cdot \mathrm{NH}_{4}}$ with sulphur, $\mathrm{H}_{2} \mathrm{~S}$ is eliminated, giving rise to two molecules of diammonium monosulphide $\left(\mathrm{NH}_{3}\right)_{2} \mathrm{~S}$, which by combination with five atoms of sulphur form the compound $\left(\mathrm{NH}_{4}\right)_{4} \mathrm{~S}_{7}$, thus $\underset{\mathrm{NH}_{4}}{\mathrm{NH}_{4}}>\underset{\mathrm{S}_{\tilde{j}}}{\mathrm{~S}-\mathrm{S}}<\frac{\mathrm{NH}_{4}}{\mathrm{NH}_{4}}$.

\section{Preparation of Crystals of Ammonium Monosulphide.}

Since the strong solution just described does not behave like one of ammonium monosulphide, and as no crystals of monosulphide could be obtained from the solution, an attempt was made to obtain crystals of the monosulphide by the union of the dry gases.

The method given by L. Gmelin (Handbock of Chemistry, 2, 451) is to pass a mixture of one volume of hydrogen sulphide with rather more than two of ammonia into a tube cooled down to $-18^{\circ}$. It is also stated that at ordinary temperatures the two gases combine in equal volnmes only, even when the ammonia is present in large excess. (The latter statement has been shown to be incorrect, see p. 267.)

These statements rest on the authority of Bineau (Ann. Chim. Phys., 1839, 70, 261). He passed a mixture of 6.7 c.c. $\mathrm{H}_{2} \mathrm{~S}$ with 14.8 c.c. $\mathrm{NH}_{3}$ through a tube cooled by a mixture of ice and salt, and measured the uncondensed gas $(1 \cdot 2$ c.c.), which he regarded as ammonia ; from this he concluded that two volumes of ammonia had combined with one volume of hydrogen sulphide; it was found that the monosulphide formed gave off ammonia on being removed from the freezing mixture, leaving ammonium hydrosulphide. As only about 20 milligrams of the solid could have been obtained by Bineau, it was thought advisable to repeat the experiment so as to obtain sufficient of the compound for analysis.

The apparatus employed was the same as that used for the preparation of ammonium hydrosulphide in the solid state (see p. 286). The bottle was cooled by ice and salt, and was kept in the freezing mixture for half an hour before the ammonia and hydrogen sulphide were admitted; these were dried by passing them through drying towers and tubes containing quicklime and calcium chloride respectively; and the air in the bottle was displaced by ammonia before the hydrogen sulphide was admitted, and the rate at which the gases were passed in was so adjusted that the ammonia was considerably 
in excess. The product obtained was evidently not homogeneous; glittering, micaceous crystals, resembling naphthalene in appearance, were formed, and at the same time a white, porcelain-like solid was deposited in the bottle, which subsequent experience showed to be ammonium hydrosulphide (see Bineau, loc. cit.). The crystals deposited at the neck of the bottle, where the temperature was not quite so low, evolved gas copiously $\left(\right.$ ? $\mathrm{NH}_{3}$ ), leaving a crystalline residue (? $\left.\mathrm{NH}_{4} \cdot \mathrm{HS}\right)$, and a third substance was also observed in fernlike crystals, apparently one of the compounds $\left(\mathrm{NH}_{4}\right)_{2} \mathrm{~S}, x \mathrm{NH}_{4} \cdot \mathrm{HS}$ previously described.

On removing the bottle from the freezing mixture, the micaceous crystals decomposed with great rapidity, torrents of ammonia being evolved; water was added, when the remaining crystals dissolved with great ease, the porcelain-like mass, $\mathrm{NH}_{4} \cdot \mathrm{HS}$, dissolving more slowly. The solution poured off from the undissolved hydrosulphide, and subjected to analysis, showed that the greater proportion of the mass consisted of $\mathrm{NH}_{4} \cdot \mathrm{HS}$. The experiment was repeated, using the same apparatus, but with the addition of two U-tubes, which were also kept at $-18^{\circ}$, and the ammonia was passed in greater excess. The micaceous crystals were obtained without difficulty, and presented a most beautiful appearance, reflecting a bluish-white light; but the total yield was disappointingly small. Ammonium hydrosulphide was also observed, but the fern-like crystals were not formed. On inspecting the cooled $U$-tubes connected with the outlet tube of the bottle, it was found that a yellowish, heavy liquid had condensed in the one next the bottle; this liquid was highly refractive, resembling carbon bisulphide in this respect. A few drops of this oily liquid had also collected in the second $U$-tube. On removing the tube from the freezing mixture, the liquid boiled violently, evolving torrents of ammonia, and leaving a white, crystalline residue, which, in turn, decomposed with evolution of ammonia; the final residue appeared to consist of ammonium hydrosulphide. The liquid product, therefore, was richer in ammonia than any sulphide yet obtained; it appears to have been formed by the passage of the excess of ammonia orer the crystals of ammonium monosulphide deposited in the bottle, and was subsequently condensed in the $U$ tabes. Some of this substance was doubtless formed in the previous experiment, but escaped uncondensed; this would account for the serious symptoms experienced during the first preparation by tho anthor and his assistant. When ice-cold water was added to the oily liquid before removing the $U$-tube from the freezing mixture, some ammonia was given off; the solution, which was of a light straw colour, when submitted to analysis, gave $\mathrm{NH}_{4}=3.56$ and 3.52 per cent.; $S=1.67$ per cent. These figures show that the oily liquid 
contains twice as much ammonia as ammonium monosulphide does, its composition being represented by the formula $\left(\mathrm{NH}_{4}\right)_{2} \mathrm{~S}, 2 \mathrm{NH}_{3}$. The excess of sulphur found, 1.67 per cent. as against 1.60 theory, is accounted for by the loss of ammonia during solution in water, and in the subsequent operations. A third experiment similar to the one just described was now made with the object of obtaining crystals of ammonium monosulphide as far as possible free from ammonium hydrosulphide, and also more of the volatile oily liquid in a state of purity.

Some small quantity of ammonium hydrosulphide was formed, but, on introducing ice-cold water, the thin, micaceous plates rapidly passed into solution, leaving the porcelain-like mass of $\mathrm{NH}_{4} \cdot \mathrm{HS}$, which dissolved but slowly. The solution thus obtained, when analysed, gave $\mathrm{NH}_{4}=14.70$ per cent.; $\mathrm{S}=16.50$ per cent.; $\left(\mathrm{NH}_{4}\right)_{2} \mathrm{~S}$ requires, for the amount of $\mathrm{NH}_{4}$ found, only 13.67 per cent. of sulphur.

This analysis shows that when the micaceous crystals are rapidly dissolved in ice-cold water, a solution is obtained in which the proportions of ammonium and sulphur are approximately those required by ammonium monosulphide.

A strong solution of the oily liquid was made with ice-cold water before removing the $U$-tube from the freezing mixture. The evolution of ammonia was again observed, and the solution was therefore diluted with about twice its volume of ice-cold water, to increase its stability. An analysis of the diluted solution gave $\mathrm{NH}_{4}=12.53$ and 12.48 per cent.; $\mathrm{S}=6.16$ and 6.25 per cent.; for $\left(\mathrm{NH}_{4}\right)_{2} \mathrm{~S}, 2 \mathrm{NH}_{3}$, the $\mathrm{NH}_{4}$ found requires $\mathrm{S}=5.55$ per cent.

This confirms the experience, that on making the first concentrated aqueous solution of the oily liquid in the $U$-tube there is loss of ammonia, this loss being due to insufficient dilution.

To the present statements concerning ammonium monosulphide must be added these facts.

1. Passing dry ammonia and dry hydrogen sulphide into a bottle cooled to $-18^{\circ}$ does not yield ammonium monosulphide alone, even when the ammonia is in considerable excess. Ammonium hydrosulphide is also formed, but by carefully adjusting the volumes of the gases and the rate of flow, ammonium monosulphide can be obtained in the form of micaceous crystals. When these crystals are rapidly dissolved in ice-cold water, a solution is obtained approximating sufficiently closely to the composition $\left(\mathrm{NH}_{1}\right)_{2} \mathrm{~S}$ to justify the conclusion that the micaceous crystals are ammonium monosulphide. This view is also supported by the behaviour of the crystals when the temperature rises, ammonia being copiously evolved and a residue of ammonium hydrosulphide left. 
2. If the ammonia is largely in excess, then a more volatile sulphide is obtained, containing more ammonia than ammonium monosulphide, and having the composition $\left(\mathrm{NH}_{4}\right)_{2} \mathrm{~S}, 2 \mathrm{NH}_{3}$.

\section{The Polysulphides of Ammonium.}

Our knowledge concerning the polysulphides of ammonium is mainly based on the work of Fritzsche, as detailed in his two papers"On Two Crystalline Compounds of Ammonium with Sulphur" (J. pr. Chem., 1841, 24, 460), "On Tetrasulphide of Ammoninm" (ibid., 1844, 32, 313). A condensed, but not wholly accurate, account of Fritzsche's work is given in Watt's Dict. (new edition), I, 204.

Fritzsche claims to have obtained diammonium tetrasulphide, pentasulphide, and heptasulphide; his results will be criticised in the portions of this paper which deal with the preparation of these salts.

Fritzsche's attempt to prepare diammonium trisulphide and disulphide, by continued treatment of the mother liquor, from which he claimed to have obtained the tetrasulphide, resulted in failure. The mother liquors from which the diammonium pentasulphide and tetrasulphide had crystallised were not analysed by him.

Diammonium Pentasulphide.-The investigation of the products formed when aqueous ammonia is saturated with hydrogen sulphide, showed that the solution Fritzsche employed as his starting point for the preparation of diammonium pentasulphide, which he believed to contain ammonium hydrosulphide, could not have had that composition. Most probably it was made by saturating strong ammonia solution with bydrogen sulphide, in which case the product, if completely saturated, would have been of the approximate composition $\left(\mathrm{NH}_{4}\right)_{2} \mathrm{~S}, 2 \mathrm{NH}_{4} \cdot \mathrm{HS}$, and if incompletely saturated, the composition $\left(\mathrm{NH}_{4}\right)_{2} \mathrm{~S}, 2 \mathrm{NH}_{4} \cdot \mathrm{HS}, x \mathrm{NH}_{4} \cdot \mathrm{HO}$, that is approximating to ammonium monosulphide. Under these circumstances it was considered preferable to act with sulphur on a solution containing the ammonium and sulphur in the ratio $2 \mathrm{NH}_{4}: \mathrm{S}$ (see p. 290). When a solution of about 40 per cent. concentration was warmed with excess of sulphur, in the form of impalpable powder, the temperature being gradually allowed to rise to $80^{\circ}$, there was a very brisk action, hydrogen sulphide was evolved in quantity, and the sulphur dissolved rapidly, the solution appearing almost black. On cooling, crystals separated, but on attempting to dissolve them by the addition of water, the crystals were immediately decomposed, sulphur being deposited and a pale yellow solution obtained.

The following experiment with a more dilute solution was then made. 200 c.c of the 40 per cent. solution were placed in a flask, diluted with 75 c.c of water, and sulphur added in greater excess than would be required for the formation of diammonium pentasulphide; 
the mixture was then gently warmed on a water bath, the temperature not being allowed to exceed $80^{\circ}$. As before, much hydrogen sulphide was erolved, the sulphur dissolved freely, and the liquid became deep red. When the action was complete, the liquid was poured off from the undissolved sulphur into a flask and left standing overnight. In the morning a crop of fine large yellow oblique prisms had formed; the crystals exhibiting the features noted by Fritzsche as characteristic of diammonium pentasulphide. The mother liquor was poured off from the crystals and reserved for analysis in closely stoppered bottles. The crystals were at once analysed, and gave $\mathrm{NH}_{4}=18 \cdot 14$ and $18 \cdot 1 \mathrm{~L}$ per cent.; $S=81 \cdot 28$ per cent. They are therefore anhydrous diammonium pentasulphide.

Calculated for $\left(\mathrm{NH}_{4}\right)_{2} \mathrm{~S}_{6} . \quad \mathrm{S}=81.63 ; \mathrm{NH}_{4}=18.37$.

The mother liquor from the crystals of diammonium pentasulphide could not be a solution of $\left(\mathrm{NH}_{4}\right)_{2} \mathrm{~S}_{6}$, as much hydrogen sulphide had been evolved during the action, and the mother liquor must consequently contain free ammonia. On cooling this mother liquor in a freezing mixture, a crystalline mass was deposited, which was rapidly washed with alcohol after the liquid portion had been poured off; on allowing the crystals to liquefy at a gentle heat, a solution of the substance in its own water of hydration was obtained, and there was no deposition of sulphur. On analysis it gave $\mathrm{NH}_{4}=9 \cdot 35$ and 9.32 per cent. Total $S=37 \cdot 15$ and 36.83 per cent. $S$ as polysulphide $=28 \cdot 67$ and $28 \cdot 67$ per cent.

This analysis shows that the ratio $\mathrm{S} / \mathrm{NH}_{4}$ in this solution is 3.98 . A pure solution of diammonium pentasulphide would give the ratio $\mathrm{S} / \mathrm{NH}_{4}=4 \cdot 44$, and consequently the above preparation contains polysulphides lower than pentasulphide. Another preparation yielded precisely similar results. It is to be remarked here that the crystalline masses obtained on freezing, and which yielded the above solutions, had the composition $\left(\mathrm{NH}_{4}\right)_{2} \mathrm{~S}_{4 \cdot 5}$ or $\left(\mathrm{NH}_{4}\right)_{4} \mathrm{~S}_{9}$.

On cooling a portion of one of these solutions in a freezing mixture, crystals were deposited as usual, but, after the mother liquor had been poured off, they did not entirely dissolre on warming to $50^{\circ}$, as on previous occasions. These crystals were richer in sulphur than $\left(\mathrm{NH}_{4}\right)_{2} \mathrm{~S}_{6}$, whilst the mother liquor had approximately the composition of diammonium tetrasulphide, $\left(\mathrm{NH}_{4}\right)_{2} \mathrm{~S}_{4}$.

It was concluded, then, that at this stage the red liquors contained a series of polysulphides, probably diammonium heptasulphide, $\left(\mathrm{NH}_{4}\right)_{2} \mathrm{~S}_{7}$; pentasulphide, $\left(\mathrm{NH}_{4}\right)_{2} \mathrm{~S}_{5}$; tetrasulphide, $\left(\mathrm{NH}_{4}\right)_{2} \mathrm{~S}_{4}$; and, possibly, disulphide, $\left(\mathrm{NH}_{4}\right)_{2} \mathrm{~S}_{2}$. 
Attempts to prepare Polysulphides by the Action of Reputed Solution of Diammonium Monosulphide on Sulphur in Sealed Tubes.

The method of preparation previously described being complicated, and involving loss of bydrogen sulphide, crystallisation, \&c., it was thought that possibly the formation of a series of polysulphides might be due to this canse. It is generally stated that diammonium disulphide, $\left(\mathrm{NH}_{4}\right)_{2} \mathrm{~S}_{2}$, is obtained when sulphur is dissolved in the monosulphide in the proportion $\left(\mathrm{NH}_{4}\right)_{2} \mathrm{~S}: \mathrm{S}$; experiments were, therefore, made to test the truth of this statement, as, if it were true, the higher polysulphides should be obtained by a similar process.

The solution used was one previously described (p. 290), which, whilst giving analytical results corresponding to those required for diammonium monosulphide, was, as previously stated, regarded with suspicion. It was, however, the only solution available for the purpose, and the preparation of diammonium disulphide, if effected previously, must have been made with a similar solution.

The method adopted was as follows. Quantities of 15 c.c. of the reputed solution of diammonium monosulphide (of known strength) were placed in glass tubes, and to each was added the calculated amount of sulphar for a definite polysulphide. The tubes were then. sealed, and, with the exception of that for diammonium disulphide, $\left(\mathrm{NH}_{4}\right)_{2} \mathrm{~S}_{2}$, placed in a capacions beaker containing cold water, the temperature of which was gradually raised. An evolution of gas was in each case observed where the sulphur was being dissolred. If the solution were one of diammonium monosulphide, this should not occur.

I. Attempted formation of $\left(\mathrm{NH}_{4}\right)_{2} \mathrm{~S}_{5}$ [15 c.c. reputed $\left(\mathrm{NH}_{4}\right)_{2} \mathrm{~S}$ solution $+11 \cdot 22$ grams S].--I'he sulphur was, at first, rapidly dissolved, afterwards more slowly, and then, whilst a considerable mass of sulphur was still undissolved, the solution suddenly solidified, a mass of small, needle-shaped crystals being obtained. On heating to $100^{\circ}$, a little more sulphur was dissolved, but as a large portion still remained undissolved, the tube was heated for three hours in an air. bath at $120^{\circ}$. The sulphur melted, but no further action was observed. The solution was deep red, and almost opaque, when viewed by transmitted light; on cooling, a crystalline mass, mixed with sulphur, was deposited, which was useless for analysis.

In a second experiment with a more dilute solution, a still larger residue of sulphur remained undissoived, indicating that dilution was unfavourable to solution of the sulphur. These experiments showed that the power of dissolving sulphur, possessed by reputed solution of diammonium monosulphide, was greatly below the limits required 
to form diammonium pentasulphide; experiments were, therefore, made to prepare the lower members of the series.

II. Attempted formation of $\left(\mathrm{NH}_{4}\right)_{2} \mathrm{~S}_{2}$ [15 c.c. reputed $\left(\mathrm{NH}_{4}\right)_{2} \mathrm{~S}$ solution +2.8 grams S].-A yellow solntion was obtained from the commencement, the sulphur being almost completely dissolved in the cold; on warming slightly, a clear, reddish-yellow solution was obtained. There was no deposition of crystals at the ordinary temperature, but, on cooling with ice and salt, tufts of small, yellow needles separated after a time. There was no pressure on opening the tube. The crystals from the mother liquor were separated, rapidly dried between filter-paper, and transferred to stoppered weighing tubes. These crystals dissolved in water, giving a clear, yellow solution, which did not deposit sulphur for a considerable time. On analysis, the crystals gave $\mathrm{S}=61.05, \mathrm{NH}_{4}=19.68$, $\mathrm{H}_{2} \mathrm{O}$ (by difference) $=19 \cdot 27$ per cent.

Although the substance was obtained in well-formed crystals, its composition does not accord with any known ammonium sulphide; if they be represented by the formula $\left(\mathrm{NH}_{4}\right)_{4} \mathrm{~S}_{7}, 4 \mathrm{H}_{2} \mathrm{O}$, tetrammonium heptasulphide, they should contain $\mathrm{S}=60 \cdot 88, \mathrm{NH}_{4}=19 \cdot 56, \mathrm{H}_{2} \mathrm{O}=$ 19.56 per cent.

III. Attempted formation of $\left(\mathrm{NH}_{4}\right)_{2} \mathrm{~S}_{3}\left[15\right.$ c.c. reputed $\left(\mathrm{NH}_{4}\right)_{2} \mathrm{~S}$ solution $+5 \cdot 61$ grams $\mathbf{S}]$. - On shaking in the cold, part of the sulphur dissolved, and then crystallisation took place.* On wurming to $70-80^{\circ}$, an orange-red solution was obtained, which, after remaining for some time at the ordinary temperature, deposited rosettes of fine needles. After the crystals had been separated from mother liquor, as in the previous experiment, water was added in the usual course of analysis, when they were at once decomposed, sulphur being deposited.

The results of analysis show that the crystals are diammonium pentasulphide with $1 \mathrm{H}_{2} \mathrm{O}$.

$\begin{array}{lccc} & \mathrm{S} . & \mathrm{NH}_{4} & \mathrm{H}_{2} \mathrm{O} . \\ \text { Calculated for }\left(\mathrm{NH}_{4}\right)_{2} \mathrm{~S}_{5}, \mathrm{H}_{2} \mathrm{O} . . & 74 \cdot 77 & 16 \cdot 82 & 8 \cdot 41 \text { per cent. } \\ \text { Found } \ldots \ldots \ldots \ldots \ldots \ldots \ldots \ldots \ldots & 74.79 & 16.94 & (8 \cdot 27) \quad,\end{array}$

This salt differs from diammonium pentasulphide previously obtained (p. 296) in containing $1 \mathrm{H}_{2} \mathrm{O}$. In form it is easily distinguished from the oblique prisms of the anhydrous pentasulphide, the monhydrated salt occurring in rosettes built up of fine-pointed needles. Both salts are decomposed rapidly by water, sulphur being deposited. This is noteworthy, as in Watt's Dictionary of Chemistry (Morley and Muir, $1,204)$ it is stated that $\left(\mathrm{NH}_{4}\right)_{2} \mathrm{~S}_{6}$, in the form of orange-red prismatic crystals, is easily soluble in water and alcohol, although

* Later experiments proved this crystalline product to be $\left(\mathrm{NH}_{4}\right)_{4} \mathrm{~S}_{7}$ tetrammonium heptasulphide. 
Fritzsche states that the pentasulphide is decomposed by water yielding a lemon-coloured solution of a compound containing less sulphur whilst sulphur is deposited.

IV. Attempted formation of $\left(\mathrm{NH}_{4}\right)_{2} \mathrm{~S}_{4}\left[15\right.$ c.c. reputed $\left(\mathrm{NH}_{4}\right)_{2} \mathrm{~S}$ solution +8.42 grams $\mathrm{S}]$. - The sulphur dissolved with difficulty, but solution was complete at about $80^{\circ}$, and a deep red solution was obtained which appeared black by reflected light. On cooling, crystallisation took place, very little mother liquor being left. The crystals were yellow needles. After the crystals had been separated, as in the previous experiments, the addition of water for the purpose of analysis decomposed them, sulphur being deposited.

The results of analysis show that the crystals are tetrammonium enneasulphide $\left(\mathrm{NH}_{4}\right)_{4} \mathrm{~S}_{9}+3 \frac{1}{2} \mathrm{H}_{2} \mathrm{O}$.

S. $\quad \mathrm{NH}_{4} . \quad \mathrm{H}_{2} \mathrm{O}$.

Calculated for $\left(\mathrm{NH}_{4}\right)_{4} \mathrm{~S}_{9}, 3 \frac{1}{2} \mathrm{H}_{2} \mathrm{O} \quad 68.08 \quad 17.02 \quad 14.90$ per cent.

Found............... 68.35 16.98 (14.67) ,

The results of the preceding experiments are given in a tabular form to facilitate reference.

Table showing Results obtained by the Action of Reputed Ammonium Sulphide Solution on Sulphur in Sealed Tubes.

\begin{tabular}{|c|c|c|c|c|}
\hline \multirow{2}{*}{$\begin{array}{l}\text { Attempted } \\
\text { formation of }\end{array}$} & \multicolumn{2}{|c|}{ Proportions used of } & \multirow{2}{*}{$\begin{array}{l}\text { Residue of } \\
\text { sulphur. }\end{array}$} & \multirow{2}{*}{ Product. } \\
\hline & $\begin{array}{c}\left(\mathrm{NH}_{4}\right)_{2} \mathrm{~S} \\
\text { sol. c.c. }\end{array}$ & $\begin{array}{l}\text { Sulphur } \\
\text { (grams). }\end{array}$ & & \\
\hline$\left(\mathrm{NH}_{4}\right)_{2} \mathrm{~S}_{5} \ldots$ & 15 & $11 \cdot 22$ & Large........ & $\begin{array}{l}\text { Solid mass of crystals mixed } \\
\text { with sulphur. }\end{array}$ \\
\hline$\left(\mathrm{NH}_{4}\right)_{2} \mathrm{~S}_{4} \ldots$ & 15 & $8 \cdot 42$ & $\begin{array}{l}\text { No residue, } \\
\text { but } \mathbf{S} \text { dis- } \\
\text { solves with } \\
\text { difficulty }\end{array}$ & $\begin{array}{l}\text { Solid mass of crystals of } \\
\text { composition }\left(\mathrm{NH}_{4}\right)_{4} \mathrm{~S}_{9}+ \\
3 \frac{1}{2} \mathrm{H}_{2} \mathrm{O} \text {. }\end{array}$ \\
\hline$\left(\mathrm{NH}_{4}\right)_{2} \mathrm{~S}_{3} \ldots$ & 15 & $5-61$ & None ........ & $\begin{array}{l}\text { Crystals of }\left(\mathrm{NH}_{4}\right)_{2} \mathrm{~S}_{5}+ \\
\mathrm{H}_{2} \mathrm{O} \text {, the motherliquor se- } \\
\text { parated containing lower } \\
\text { sulphides. }\end{array}$ \\
\hline$\left(\mathrm{NH}_{4}\right)_{2} \mathrm{~S}_{2} \ldots$ & 15 & $2 \cdot 8$ & None ........ & $\begin{array}{l}\text { Mother liquor separated. } \\
\text { Crystals of }\left(\mathrm{NH}_{4}\right)_{4} \mathrm{~S}_{7}+ \\
4 \mathrm{H}_{2} \mathrm{O} \text {. }\end{array}$ \\
\hline
\end{tabular}

The following conclusions are drawn from the preceding experiments.

1. That the solution employed, giving analytical results corresponding with those required by diammonium monosulphide, is not in reality a solution of that substance. 
2. That this solution is to be regarded as containing, not $\left(\mathrm{NH}_{4}\right)_{2} \mathrm{~S}$ simply, but the compound $\left(\mathrm{NH}_{4}\right)_{2} \mathrm{~S}_{2} 2 \mathrm{NH}_{4} \cdot \mathrm{HS}+2 \mathrm{NH}_{4} \cdot \mathrm{HO}$.

3 . That the lower polysulphides cannot be obtained by dissolving the calculated amount of sulphur in this solution.

4. That when sulphur acts on this solution, hydrogen sulphide is eliminated (which would not take place were the solution one of diammonium rnonosulphide) and two definite polysulphides are obtained, namely, $\left(\mathrm{NH}_{4}\right)_{4} \mathrm{~S}_{7}$, tetrammonium heptasulphide, and $\left(\mathrm{NH}_{4}\right)_{4} \mathrm{~S}_{9}$, tetrammonium enneasulphide.

5. In no case is more sulphur taken up than is required for the formation of the compound $\left(\mathrm{NH}_{4}\right)_{4} \mathrm{~S}_{9}$.

Previous experiments seemed to show that the complex polysulphides obtained might be due to the constitution of the reputed $\left(\mathrm{NH}_{4}\right)_{2} \mathrm{~S}$ solution, that is $\left(\mathrm{NH}_{4}\right)_{2} \mathrm{~S}, 2 \mathrm{NH}_{4} \cdot \mathrm{HS}+2 \mathrm{NH}_{4} \cdot \mathrm{HO}$. When acted on by sulphur, $\left(\mathrm{NH}_{4}\right)_{2} \mathrm{~S}, 2 \mathrm{NH}_{4} \cdot \mathrm{HS}$ parts with $\mathrm{H}_{2} \mathrm{~S}$, and the residual group, $\left(\mathrm{NH}_{4}\right)_{4} \mathrm{~S}_{2}$, is able to take up 5 and 7 atoms of sulphur respectively, forming the complex polysulphides $\left(\mathrm{NH}_{4}\right)_{4} \mathrm{~S}_{7}$ and $\left(\mathrm{NH}_{4}\right)_{4} \mathrm{~S}_{9}$. It appeared probable, therefore, that if sulphur were presented to diammonium monosulphide $\left(\mathrm{NH}_{4}\right)_{2} \mathrm{~S}$ at the moment of its formation, the action would be simpler in its character, and that in this manner a solution of diammonium pentasulphide might possibly be obtained.

Preliminary experiments showed that if a tolerably concentrated solution of ammonia were treated with hydrogen sulphide in the presence of excess of sulphur, the latter was rapidly dissolved, the solution acquired the deep red colour characteristic of solutions of polysulphides, whilst no hydrogen sulphide escaped until sulphur ceased to be dissolved. An examination of the product showed that no oxidised sulphur was present, and that it contained neither free ammonia nor ammoninm hydrosulphide. This new method of preparing polysulphide liquors was consequently adopted in all subsequent experiments. Attempts were now made to prepare a solution of diammonium pentasulphide by this direct method. A preliminary experiment showed that if strong ammonia solution were treated with hydrogen sulphide in the presence of excess of sulphur, the product, as it cooled, solidified completely, thereby defeating the purpose proposed. Accordingly strong ammonia solution was diluted with an equal volume of water, excess of finely-divided sulphur added, and washed hydrogen sulphide passed in; the sulphur dissolved rapidly and a deep red liquid was obtained. When the temperature of the solution fell and the hydrogen sulphide passed through without being absorbed, it was poured into a flask and allowed to stand overnight; some crystals of auhydrous diammonium pentasulphide were deposited, but the quantity was not large. Analysis of the mother liquor showed that the ratio $\mathrm{NH}_{4}: \mathrm{S}$ was below that 
required for diammonium pentasulphide, being that required for a substance of the composition $\left(\mathrm{NH}_{4}\right)_{4} \mathrm{~S}_{9}$.

Repeated experiments showed that in the solution the product was invariably $\left(\mathrm{NH}_{4}\right)_{4} \mathrm{~S}_{9}$; and although crystals of anhydrous diammonium pentasulphide, $\left(\mathrm{NH}_{4}\right)_{2} \mathrm{~S}_{5}$, could be obtained from it with ease, a solution of diammonium pentasulphide could not be prepared. This definitely showed that a solution of diammonium pentasulphide could not be obtained either by directly dissolving sulphur in a reputed solution of diammonium monosulphide or by treating a tolerably concentrated ammonia solution simultaneously with hydrogen sulphide and sulphur, the product in solution being identical in both cases, namely tetrammonium enneasulphide, $\left(\mathrm{NH}_{4}\right)_{4} \mathrm{~S}_{9}$.

\section{Diammonium Tetrasulphide.}

Attention was now devoted to obtaining crsstalline diammonium tetrasulphide, $\left(\mathrm{NH}_{4}\right)_{2} \mathrm{~S}_{4}$. This substance has been studied by Fritzsche (J. pr. Chem., 1844, 32, 313). After describing the method of procedure and some properties of the salt, he states that, on account of its instability, it is difficult to weigh the substance accurately for analysis, and for this reason concordant analytical results cannot be expected.

In order to test Fritzsche's method of preparing diammonium tetrasulphide, the following experiment was performed, following his directions as closely as possible. The mother liquor which had deposited crystals of diammonium pentasulphide (and containing a compound of the composition $\left.\left(\mathrm{NH}_{4}\right)_{4} \mathrm{~S}_{9}\right)$ was cooled by ice, and treated alternately with ammonia and hydrogen sulphide, when an almost solid crystalline yellow magma was obtained, as observed by Fritzsche. Gently heating this on the water bath, the crystals dissolved, and a considerable amount of gas was evolved. On cooling, fern-like crystals were deposited, which, after the mother liquor had been poured off, were analysed. The ammonia values obtained (23.08 and 23.69 per cent. $\mathrm{NH}_{4}$ ) were not constant, and were too high for diammonium tetrasulphide, which would only contain 22 per cent. $\mathrm{NH}_{4}$. The crystals were redissolved in a little water at $40^{\circ}$, and the solution allowed to cool; the crystals which were deposited were analysed with the following results: $-S=72.00 ; 74.65$ per cent. $\mathrm{NH}_{4}=17.94 ; 18.03$ per cent. The substance is evidently not a definite compound, since a variation of $2 \cdot 6$ per cent. is observed in the two determinations of sulphur. The percentage of ammonium has fallen, and does not correspond with that of any definite salt. The mother liquor from the first crop of crystals was now treated in the same fashion alternately with ammonia and hydrogen sulphide, to give the method every chance of yielding tetrasulphide. 
yellowish, feathery, crystalline mass was obtained, which was separated from the mother liquor, pressed, \&c., and analysed. It gave $\mathrm{S}=57.52$ and $56.56 . \quad \mathrm{NH}_{4}=33.38$ and 33.63 per cent.

The solution of the crystals was only faintly yellow, and the treatment with acid showed that it contained but a very small amount of polysulphide sulphur. Apparently a high multiple grouping, $\left(\mathrm{NH}_{4}\right)_{2} \mathrm{~S}, x \mathrm{NH}_{4} \cdot \mathrm{HS}$, had crystallised out, the trace of polysulphide observed being due to adberent mother liquor which it is difficult to remore, owing to the nature of the crystals.

It seems probable that the result of passing ammonia and hydrogen sulphide alternately through the polysulphide solution, $\left(\mathrm{NH}_{4}\right)_{4} \mathrm{~S}_{9}$, is that this polysulphide is precipitated together with com. pounds of the form $\left(\mathrm{NH}_{4}\right)_{2}, \mathrm{~S}_{x} \mathrm{NH}_{4} \cdot \mathrm{HS}$.

Fritzsche's process was therefore modified. The polysulphide solution was treated alternately with ammonia and hydrogen sulphide as before, but when the semi-solid mass of crystals had formed, the motber liquor was carefully poured off, and they were dissolved in a small quantity of water at $40-50^{\circ}$. On cooling, yellow needles were deposited, which, when recrystallised from a small quantity of water, gave crystals of anhydrous diammonium pentasulphide. The mother liquor from these yellow needles, when cooled in a freezing mixture, deposited a yellow crystalline mass, the mother liquor was poured off, and the crystals dissolved in their water of crystallisation by warming to $20-30^{\circ}$. The fine yellow crystals deposited on cooling were analysed, and gave $\mathrm{NH}_{4}=21.62$ and 21.67 per cent. Total, $\mathrm{S}=76.00$ and 76.10 per cent. $\mathrm{S}$ (polysulphide) $=56.79$ per cent.

These figures show that the crystals are those of hydrated diammonium tetrasulphide, having this composition, $\left(\mathrm{NH}_{4}\right)_{2} \mathrm{~S}_{4}, \frac{1}{4} \mathrm{H}_{2} \mathrm{O}$ or $4\left\{\left(\mathrm{NH}_{4}\right)_{2} \mathrm{~S}_{4}\right\}, \mathrm{H}_{2} \mathrm{O}$.

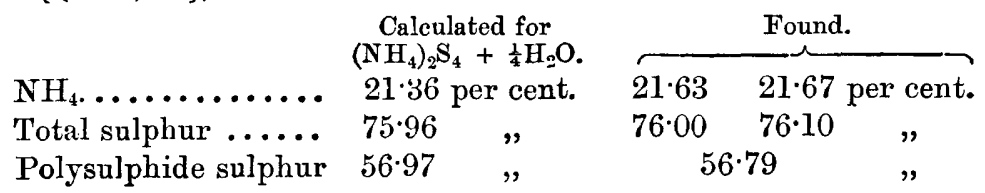

It is thus shown that, on treating a solution of tetrammonium enneasulphide, $\left(\mathrm{NH}_{4}\right)_{4} \mathrm{~S}_{9}$, alternately with ammonia and h5drogen sulphide, a yellow crystalline magma is obtained, which, by a modification of Fritzsche's method, can be separated into diammonium pentasulphide, $\left(\mathrm{NH}_{4}\right)_{2} \mathrm{~S}_{5}$, and diammonium tetrasulphide, $\left(\mathrm{NH}_{4}\right)_{2} \mathrm{~S}_{4}$. The following explanation of the mode of separation is offered.

1. Alternate treatment of solution of tetrammonium enneasulphide with ammonia and hydrogen sulphide determines the precipitation of practically the whole of the polysulphide as a yellow crystalline mass composed of $\left(\mathrm{NH}_{4}\right)_{4} \mathrm{~S}_{9}$ and compounds of the type $\left(\mathrm{NH}_{4}\right)_{2} \mathrm{~S}, x \mathrm{NH}_{4} \cdot \mathrm{HS}$. 
2. On treating this mixture with a small quantity of water at $40-50^{\circ},\left(\mathrm{NH}_{4}\right)_{4} \mathrm{~S}_{9}$ dissolves without deposition of sulphur, owing to the presence of the compounds $\left(\mathrm{NH}_{4}\right)_{2} \mathrm{~S}, x \mathrm{NH}_{4} \cdot \mathrm{HS}$. On cooling, yellow needles are deposited, $\left[\left(\left(\mathrm{NH}_{4}\right)_{2} \mathrm{~S}_{5},\left(\mathrm{NH}_{4}\right)_{2} \mathrm{~S}, x \mathrm{NH}_{4} \cdot \mathrm{HS}\right.\right.$ ? $\left.)\right]$, which yield pure anhydrous diammonium pentasulphide on recrystallisation.

3. The mother liquor from these yellow needles deposited diammonium tetrasulphide on cooling, and in this way hydrated diammonium tetrasulphide can be obtained in a state of purity.

A consideration of Fritzsche's method for preparing the tetrasulphide renders it evident that he believed the solution, from which crystals of anhydrous diammonium pentasulphide had been deposited, still contained that substance, and he relied on the power of ammonia and hydrogen sulphide to effect a reduction of the pentasulphide to tetrasulphide. In order to determine whether such reduction took place, crystals of diammonium pentasulphide were dissolved in strong ammonia solution, and treated with hydrogen sulphide; but no reduction to diammonium tetrasulphide was observed, crystalline masses of the pentasulphide and $\left(\mathrm{NH}_{4}\right)_{2} \mathrm{~S}, x \mathrm{NH}_{4} \cdot \mathrm{HS}$ groups being obtained. Fritzsche's description of the properties of his diammonium tetrasulphide is not in agreement with the behaviour of the pure salt, which is at once dissociated by water, with deposition of sulphur. Fritzsche states (J.pr. Chem., 1844, 32, 313) that " tetrasulphide of ammonium is easily soluble in water, and a concentrated solution can be kept without decomposition if well-boiled water has been used for its solution."

Fritzsche's remarks are explained by the fact that the product obtained is not pure tetrasulphide, but contains $\left(\mathrm{NH}_{4}\right)_{2} \mathrm{~S}, x \mathrm{NH}_{4} \cdot \mathrm{HS}$ groups. The presence of these prevents precipitation of sulphur from the tetrasulphide in a strong solution, and retards its precipitation if the solution be diluted.

\section{Diammonium Trisulphide.}

Fritzsche (loc. cit.) attempted to prepare the trisulphide by the continued action of ammonia and hydrogen sulphide on the mother liquor from which his reputed tetrasulphide was obtained. He says, "In this endeavour I have not been successful. Although I obtained some colourless crystals in large laminæ, they proved on examination to be anhydrous hydrosulphide of ammonium (which therefore can be produced in the wet way)."

Fritzsche does not give details of the experiments by which he convinced himself that these crystals were ammonium hydrosalphide; the author's experiments proved, howerer, that the final product roL. LXVII. 
obtained on treating polysulphide solutions (which had yielded crystals of diammonium pentasulphide and diammonium tetrasulphide) alternately with ammonia and hydrogen sulphide was not ammonium hydrosulphide. The analysis of this final productnamely, $\mathrm{NH}_{4}=33.81$ and 33.79 per cent.; $\mathrm{S}=56.68$ and 56.73 per cent.-corresponds approximately with that required by the formula $\left(\mathrm{NH}_{4}\right)_{2} \mathrm{~S}, 24 \mathrm{NH}_{4} \cdot \mathrm{HS}$. The small amount of polysulphide mother liquor which the crystals retain after pressing between filter-paper prevents an accurate determination of their composition.

Attempts previously made (vide p. 298) to prepare diammonium trisulphide, $\left(\mathrm{NH}_{4}\right)_{2} \mathrm{~S}_{3}$, by the action of reputed solution of $\left(\mathrm{NH}_{4}\right)_{2} \mathrm{~S}$ on the calculated amount of sulphur in a sealed tube resulted in the production of hydrated diammonium pentasulphide, $\left(\mathrm{NH}_{4}\right)_{2} \mathrm{~S}_{5}, \mathrm{H}_{2} \mathrm{O}$.

Fritzsche (J. pr. Chem., 1841, 24, 460) states that ammonium pentasulphide, when treated with water, gives a lemon-coloured solution of a compound containing less sulphur. Watt's Dictionary (Morley and Muir, 1, 204) states that $\left(\mathrm{NH}_{4}\right)_{2} \mathrm{~S}_{5}$ occur's as orange-red prismatic crystals, easily soluble in water and alcohol (although the study of ammonium sulphides is attributed to Fritzsche). Experiments showed that both diammonium pentasulphide and diammonium tetrasulphide are decomposed by water, depositing sulphur and yielding yellow solutions. It was therefore considered possible that solutions of diammonium trisulphide and disulphide might be obtained by the decomposition of the higher polysulphides by water. The experiment was accordingly made, diammonium pentasulphide being selected on account of the ease with which it is obtained in a state of purity (p. 295). The crystals were rapid ly transferred to a wide-mouthed, stoppered bottle, an 1 cold, recently-boiled water added until no further precipitation of sulphur followed the addition of a small quantity of water. The clear, bright goldenyellow solution thus obtained must contain either a mixture of polysulphides lower than tetrasulphide (trisulphide and disulphide) or one of them.

From the results of the analysis-namely, $\mathrm{NH}_{4}=0.69,0.68$, and 0.68 per cent. ; total $\mathrm{S}=2.05$ per cent.; polysulphide $\mathrm{S}=1.37$ per cent.-it is concluded that the solution is one of diammonium trisulphide $\left(\mathrm{NH}_{4}\right)_{2} \mathrm{~S}_{3}$, the ratio of the polysulphide sulphur to that as $\left(\mathrm{NH}_{4}\right)_{2} \mathrm{~S}$ being as $2: 1$.

Total sulphur found ......... 2.05 per cent.

Sulphur as polysulphide $\ldots \ldots \ldots . .61 .37 \quad$ "

Sulphur as $\left(\mathrm{NH}_{4}\right)_{2} \mathrm{~S} \ldots \ldots \ldots \ldots \overline{0.68}$ " 


\section{Diammonium Disulphide.}

The statement that "An aqueous solition may be prepared by dissolving $\mathrm{S}$ in $\left(\mathrm{NH}_{4}\right)_{2} \mathrm{~S}, \mathrm{Aq}$ in the proportion $\left(\mathrm{NH}_{4}\right)_{2} \mathrm{~S}: \mathrm{S}$ " (Watt's Dictionary, Morley and Muir, 1, 204) has been proved to bəerroneous (see p. 298), the polysulphide obtained under these conditions being hydrated tetrammonium heptasulphide, $\left(\mathrm{NH}_{4}\right)_{4} \mathrm{~S}_{7}, 4 \mathrm{H}_{2} \mathrm{O}$.

A second method (Watt's Dict., Morley and Muir, loc. cit.) consists in passing the vapour of sulphur and of ammonium chloride th rough a bot porcelain tube and then into a well-cooled receiver. On making the experiment, however, it was found that the product consisted merely of ammonium chloride and sulphur.

No authority is given for these methods, and in the latter case, having regard to the instability of the ammonium sulphides when subjected to the action of heat, the probability of obtaining a definite polysulphide by condensation, after passage through a hot tube, is somewhat remote. Up to the present, diammonium disulphide has not been obtained either in crystals or in solution.

\section{Diammonium Enneasulphide.}

In the course of these experiments, a solution of tetrammonium enneasulphide, $\left(\mathrm{NH}_{4}\right)_{4} \mathrm{~S}_{9}$, had been prepared by diluting 500 c.c. of strong ammonia solution with 150 c.c. of water, and treating simultaneously with hydrogen sulphide and excess of sulphur. The deep red solution deposited crystals of anhydrous diammonium pentasulphide on standing; as these crystals were required for experiments, the red mother liquor was poured off into a large flask, wbich was provided with a loosely-fitting cork. After some months, it was observed that a large quantity of small, hard, shining crystals of a deep red colour had been deposited; their form is difficult to distinguish, as they occur in closely-aggregated, crystalline masses. The experimental conditions were similar to those under which Fritzsche claims to have obtained diammonium heptasulphide, and for which search had been made by the author without success up to this time.

The main bulk of mother liquor was poured off into flasks loosely fitted with corks, leaving sufficient, however, to protect the crystals. Some of the crystals were pressed between filter-paper, and analysed with the following results. $\mathrm{NH}_{4}=10.81$ per cent. Total $\mathrm{S}=86.47$ and 86.55 per cent. Poljsulphide $\mathrm{S}=77.05$ per cent. The crystals were not, as expected, those of diammonium heptasulphide, but were richer in sulphur, and of the composition $\left(\mathrm{NH}_{4}\right)_{2} \mathrm{~S}_{9}, \frac{1}{2} \mathrm{H}_{2} \mathrm{O}$, hydrated diammonium enneasulphide, which would require 


$\begin{array}{lcccc} & \text { Total S. } & \mathrm{NH}_{4} . & \mathrm{H}_{2} \mathrm{O} . & \text { Polysulphide S. } \\ \text { Calculated for }\left(\mathrm{NH}_{4}\right)_{2} \mathrm{~S}_{9} \frac{1}{2} \mathrm{H}_{2} \mathrm{O} & 86.49 & 10 \cdot 81 & 2 \cdot 70 & 76.88 \text { per cent. } \\ \text { Found.................. } & 86.51 & 10.81 & (2 \cdot 68) & 77.05 \% ~\end{array}$

The mother liquor from these crystals, preserved in loosely-corked flasks, deposited another crop of crystals which, on analysis, proved to be diammonium enneasulphide, containing more water of crystallisation, $5\left(\mathrm{NH}_{4}\right)_{2} \mathrm{~S}_{9}+4 \mathrm{H}_{2} \mathrm{O}$.

This compound is remarkable as being the highest sulphide obtained; the crystals when covered with mother liquor appear almost black, but on removal from the mother liquor are seen to be of a deep ruby colour and almost opaque. If rapidly freed from mother liquor only a thin film of sulphur is formed on the crystals. If the crystals are treated with water they are decomposed, and dissolve to a limited extent, yielding a pale yellow solution of a lower sulphide, whilst a sulphur-coated crystal is left preserving the form of the original.

The behaviour of this salt with acids is characteristic; the exterior of the crystal becomes coated with a hard mass of sulpbur, which protects it against the action of dilute hydrochloric acid, even when boiled with it. In estimating the ammonium and sulphur (polysulphide), it was necessary to break down the sulphur-coated crystals with a flat-ended glass rod, the crystals being hard and vitreous, boiling with acid and repetition of the process of crushing being continued until the decomposition was complete.

The crystals of diammonium enneasulphide, if pressed with a glass rod against a hard surface, fly to pieces, the powder having the colour of finely-divided potassium dichromate.

\section{Diammonium Heptasulphide.}

Throughout these experiments, no crystals of diammonium heptasulphide had been obtained, although the pentasulphide and enneasulphide were prepared in a state of purity.

Fritzsche states $(J . p r$. Chem., 1841, 24, 460) that diammonium heptasulphide is formed from the pentasulphide while it is being drained from mother liquor; the crystals were placed in a bottle, which stood with the cork downwards in order to allow the mother liquor to drain off, air being excluded.

"After some days, many of the crystals of the pentasulphide carried new, small, ruby-coloured crystals, and others bore cavities sideways which were filled up with the new substance; that, however, only adhered loosely to the crystal out of which it had been formed. The decomposition becomes complete on standing for a longer time, especially when the vessel is large and filled with dry air. The new compound appears then in the form of a crystalline crust, resembling: in shape the original crystal, but larger and hollow in the centre." 
I found, however, that on limited exposure to air of the liquid resulting from solution of crystals of diammonium pentasulphide in their own mother liquor, crystals of sulphur are deposited, together with diammonium pentasulphide, but no red crystals such as Fritzsche described.

Diammonium heptasulphide has, howerer, been obtained by the simultaneous action of hydrogen sulphide and sulphur on solutions of ammonia ; the ammonia solutions being more concentrated than those used in preparation of diammonium pentasulphide. For instance, 200 c.c. of strong ammonia solution $(0 \cdot 880)$ were diluted with 60 c.c. of water, excess of sulphur added, and hydrogen sulphide passed to saturation, the flask and contents being kept in constant agitation to promote solution. When the hydrogen sulphide passed through the solution without being absorbed, and the temperature of the solution began to fall, the latter was carefully poured off from the undissolved sulphur into another flask. Small glistening, red crystals at once began to form, and continued to increase even when the flask was placed in warm water.

On analysis, they gave the following results: $\mathrm{NH}_{4}=12.80$ and 12.65 per cent. Total $\mathrm{S}=78.96$ per cent. Polysulphide $\mathrm{S}=66.81$ per cent.

These figures correspond to hydrated diammonium heptasulphide, $3\left(\mathrm{NH}_{4}\right)_{2} \mathrm{~S}_{7}, 4 \mathrm{H}_{2} \mathrm{O}$, for which the following values would be required.

$\begin{array}{lccc} & \mathrm{NH}_{4} & \text { Total s. } & \text { Polysulphide S. } \\ \text { Calculated for } 3\left(\mathrm{NH}_{4}\right)_{2} \mathrm{~S}_{7}, 4 \mathrm{H}_{2} \mathrm{O} & \mathbf{1 2} \cdot 67 & 78 \cdot 87 & 67 \cdot 60 \text { per cent. } \\ \text { Found } \ldots \ldots \ldots \ldots \ldots \ldots \ldots \ldots & 12 \cdot 65 & 78.96 & 66 \cdot 81 \quad,\end{array}$

The crystals when dry appeared dichroic, exhibiting a peculiar violet lustre. Examined with a lens they seemed to be tetrahedra. They maintained their form in air, becoming, however, slowly coated with sulphur. In contact with water, the crystals underwent decomposition, depositing sulphur, and yielding a pale yellow solution. They were only slowly attacked by dilute hydrochloric acid, but did not resist the action of acid so strongly as the crystals of diammonium enneasulphide.

\section{Remarkis on the Formation of Polysulphides.}

The mode of formation of the polysulphides of ammonium does not seem to be as simple as is usually considered. The statement is made that in the case of diammonium disulphide, $\left(\mathrm{NH}_{4}\right)_{2} \mathrm{~S}_{2}$, an aqueous solution may be prepared by dissolving $\mathrm{S}$ in $\left(\mathrm{NH}_{4}\right)_{2} \mathrm{~S}, \mathrm{Aq}$ in the required proportion, thus

$$
\left(\mathrm{NH}_{4}\right)_{2} \mathrm{~S}+\mathrm{S}=\left(\mathrm{NH}_{4}\right)_{2} \mathrm{~S}_{2} \text {. }
$$

On heating a solution, corresponding to $\left(\mathrm{NH}_{4}\right)_{2} \mathrm{~S}$, in sealed tubes 
with the calculated amounts of sulphur, the desired polysulphides were not obtained (see p. 297).

$$
\begin{aligned}
& \left(\mathrm{NH}_{4}\right)_{2} \mathrm{~S}+\mathrm{S} \text { gave }\left(\mathrm{NH}_{4}\right)_{4} \mathrm{~S}_{i}, 4 \mathrm{H}_{2} \mathrm{O} . \\
& \left(\mathrm{NH}_{4}\right)_{2} \mathrm{~S}+\mathrm{S}_{2}, \quad\left(\mathrm{NH}_{4}\right)_{2} \mathrm{~S}_{5}, \mathrm{H}_{2} \mathrm{O} . \\
& \left(\mathrm{NH}_{4}\right)_{2} \mathrm{~S}+\mathrm{S}_{3} \Rightarrow \quad\left(\mathrm{NH}_{4}\right)_{4} \mathrm{~S}_{9}, 3 \frac{1}{2} \mathrm{H}_{2} \mathrm{O} .
\end{aligned}
$$

It was proved that more sulphur than is represented by the last equation could not be dissolved.

On warming a moderately strong solntion of $\left(\mathrm{NH}_{4}\right)_{2} \mathrm{~S}$ with excess of sulphur in an open vessel, until no more of the latter is dissolved, allowing to cool, pouring off the deep red solution from the excess of sulphur, and cooling in a freezing mixture, a yellow crystalline mass is deposited ; this, on gently warming, dissolves in its own water of crystallisation, forming a deep red liquid. The composition of this solution is represented by the formula $\left(\mathrm{NH}_{4}\right)_{4} \mathrm{~S}_{9}$, tetrammonium enneasulphide, and in several different experiments the same compound was always produced.

It was thought possible that the fact that the simple polysulphides were not formed, was due to the constitution of the reputed solution of $\left(\mathrm{NH}_{4}\right)_{2} \mathrm{~S}$, which, as has been shown, has not this formula, but must be regarded as a solution of $\left(\mathrm{NH}_{4}\right)_{2} \mathrm{~S}, 2 \mathrm{NH}_{4} \cdot \mathrm{HS}+2 \mathrm{NH}_{4} \cdot \mathrm{HO}$.

In the hope of obtaining the simple polysulphides by the action of sulphur on $\left(\mathrm{NH}_{4}\right)_{2} \mathrm{~S}$ at the moment of its formation, another method of preparation was attempted. Hydrogen sulphide was passed into a solution of ammonia, of a strength corresponding to the solution of $\left(\mathrm{NH}_{4}\right)_{2} \mathrm{~S}, 2 \mathrm{NH}_{4} \cdot \mathrm{HS}+2 \mathrm{NH}_{4} \cdot \mathrm{HO}$ previously used, in the presence of sulphir, as already described. The solution obtained, however, had also the composition $\left(\mathrm{NH}_{4}\right)_{4} \mathrm{~S}_{9}$, and was proved to be free from ammonium hydroxide or hydrosulphide by means of the cupric sulphate test. It was also free from oxidised sulphur.

It would seem then that whichever method of preparation was adopted the polysulphides obtained contain four ammonium groups. Thus the solution containing $\left(\mathrm{NH}_{4}\right)_{2} \mathrm{~S}_{2} 2 \mathrm{NH}_{4} \cdot \mathrm{HS}+2 \mathrm{NH}_{4} \cdot \mathrm{HO}$ will dissolve sulphur in the cold with evolution of some hydrogen sulphide, and if it be agitated when no more sulphur is dissolved tetrammonium heptasulphide, $\left(\mathrm{NH}_{4}\right)_{4} \mathrm{~S}_{7}$, crystallises out.

On warming solutions containing $\left(\mathrm{NH}_{4}\right)_{2} \mathrm{~S}, 2 \mathrm{NH}_{4} \cdot \mathrm{HS}+2 \mathrm{NH}_{4} \cdot \mathrm{HO}$ with excess of sulphur, the chief product obtained is tetrammonium enneasulphide, $\left(\mathrm{NH}_{4}\right)_{4} \mathrm{~S}_{9}$.

No experimental evidence could be obtained of the direct formation of the simple or diammonium polysulphides.

It appears that when a solution containing $\left(\mathrm{NH}_{4}\right)_{2} \mathrm{~S}, 2 \mathrm{NH}_{4} \cdot \mathrm{HS}+$ $2 \mathrm{NH}_{4} \cdot \mathrm{HO}$ acts on sulphur, the compound $\left(\mathrm{NH}_{4}\right)_{2} \mathrm{~S}, 2 \mathrm{NH}_{4} \cdot \mathrm{HS}$ loses hydrogen sulphide, and, according to the conditions of experiment, takes up 5 or 7 atoms of sulphur. 
ACTION, IN THE COLD, OF DIASTASE ON STARCH-PASTF 309

$$
\begin{aligned}
& \text { (a.) }\left(\mathrm{NH}_{4}\right)_{2} \mathrm{~S}, 2 \mathrm{NH}_{4} \cdot \mathrm{HS}+\mathrm{S}_{5}=\left(\mathrm{NH}_{4}\right)_{4} \mathrm{~S}_{2} \cdot \mathrm{S}_{5}+\mathrm{H}_{2} \mathrm{~S} . \\
& \text { (b.) }\left(\mathrm{NH}_{4}\right)_{2} \mathrm{~S}, 2 \mathrm{NH}_{4} \cdot \mathrm{HS}+\mathrm{S}_{7}=\left(\mathrm{NH}_{4}\right)_{4} \mathrm{~S}_{2} \cdot \mathrm{S}_{7}+\mathrm{H}_{2} \mathrm{~S} .
\end{aligned}
$$

The saturated red liquor obtained by the action of a solution of $\left(\mathrm{NH}_{4}\right)_{2} \mathrm{~S}, 2 \mathrm{NH}_{4} \cdot \mathrm{HS}$ on sulphur cannot be induced to take up more sulphur than enough to form tetrammoninm enneasulphide $\left(\mathrm{NH}_{4}\right)_{4} \mathrm{~S}_{9}$, and it would appear that all the simple or diammonium polysulphides obtained are secondary products, formed by the decomposition of tetrammonium enneasulphide under varying conditions of temperature, concentration, \&c.

Thus, when the original saturated red solutions of the enneasulphide are of suitable strengths, the following simple or diammonium poly. sulphides can be obtained.

$$
\begin{array}{lll}
\left(\mathrm{NH}_{4}\right)_{2} \mathrm{~S}_{5}= & \text { diammonium pentasulphide. } \\
\left(\mathrm{NH}_{4}\right)_{2} \mathrm{~S}_{7}= & , & \text { heptasulphide. } \\
\left(\mathrm{NH}_{4}\right)_{2} \mathrm{~S}_{9}= & , & \text { enneasulphide. }
\end{array}
$$

But in all cases the mother liquors left after separation of the crystals have a lower sulphur value than is required by $\left(\mathrm{NH}_{4}\right)_{4} \mathrm{~S}_{9}$. Also by alternately treating a solution of the enneasulphide with ammonia and hydrogen sulphide, and by slightly modifying Fritzsche's process (see p. 302), it has been found possible to resolve tetrammonium enneasulphide, $\left(\mathrm{NH}_{4}\right)_{4} \mathrm{~S}_{9}$, into diammonium pentasulphide, $\left(\mathrm{NH}_{4}\right)_{2} \mathrm{~S}_{5}$, and diammonium tetrasulphide, $\left(\mathrm{NH}_{4}\right)_{2} \mathrm{~S}_{4}$, both these substances being obtained pure.

The study of the exact conditions under which tetrammonium enneasulphide will yield the diammonium polysulphides is greatly complicated by the circumstance that it is decomposed by water, and up to the present no vehicle has been found available for its recrystallisation.

The author wishes to express his acknowledgment of the services rendered by his assistant, Dr. W. J. McKerrow, who has in the course of this work displayed much resource in meeting the many difficulties encountered. 